\title{
COMBUSTION TURBINE (CT) HOT Section Coating Life Management
}

Semi Annual Technical Progress Report

Reporting Period Start Date: October 1, 2003 Reporting Period End Date: March 31, 2004

Agreement Number: DE-FC26-01NT41231

Principal Authors:

R. Viswanathan

D. Gandy

K. Krzywosz

S. Cheruvu

E. Wan

$\underline{\text { Subcontractors }}$

Southwest Research Institute

Turbine Technology International

R. Viswanathan/D. Gandy

3412 Hillview Avenue

Palo Alto, CA 94304

September 15, 2003

Email: davgandy@epri.com 


\section{Disclaimer}

"This report was prepared as an account of work sponsored by an agency of the United States Government. Neither the United States Government nor any agency thereof, nor any of their employees, makes any warranty, express or implied, or assumes any legal liability or responsibility for the accuracy, completeness, or usefulness of any information, apparatus, product, or process disclosed, or represents that its use would not infringe privately owned rights. Reference herein to any specific commercial product, process, or service by trade name, trademark, manufacturer, or otherwise does not necessarily constitute or imply its endorsement, recommendation, or favoring by the United States Government or any agency thereof. The views and opinions of authors expressed herein do not necessarily state or reflect those of the United States Government or any agency thereof." 


\section{TABLE OF CONTENTS}

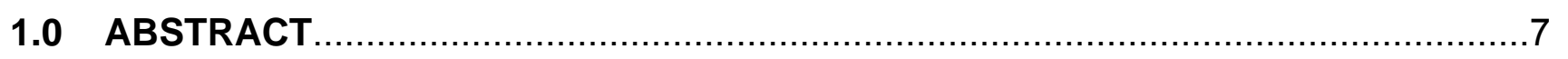

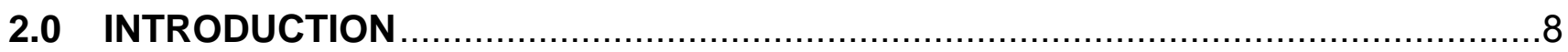

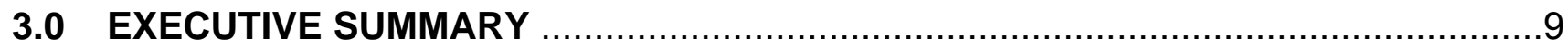

4.0 TASK 1: REFINEMENT AND VALIDATION OF HSLMP …............................12

5.0 TASK 2: COATLIFE FOR ADVANCED METALLIC COATINGS AND TBCs $\ldots \ldots \ldots \ldots . . .12$

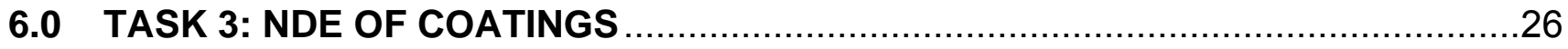

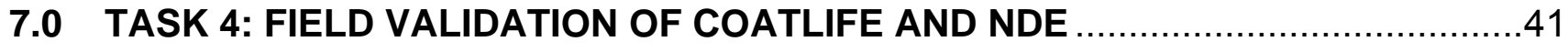




\section{LIST OF TABLES}

Table 5-1. Chemical composition of GTD-111 and IN-738 test materials (wt. \%) ............................12

Table 5-2. Chemical composition of CT102 bond coating powder (wt \%) ........................13

Table 5-3. Chemical composition of ceramic coating powder (wt.\%). ..............................13

Table 5-4: Time for TBC cracking or Spallation after Isothermal Exposure .......................14

Table 5-5: Thermal cycling between $1066^{\circ} \mathrm{C}\left(1950^{\circ} \mathrm{F}\right)$ and room temperature test results ..15

Table 5-6: Thermal cycling between $1010^{\circ} \mathrm{C}\left(1850^{\circ} \mathrm{F}\right)$ and room temperature test results ..16

Table 5-7: Thermal cycling test results at the peak temperature of $1038^{\circ} \mathrm{C} 1900^{\circ} \mathrm{F}$ ) with 24 hour hold time.

Table 5-8: Influence of exposure temperature and time on thermally grown oxide (TGO) scale thickness on TBC coated specimens

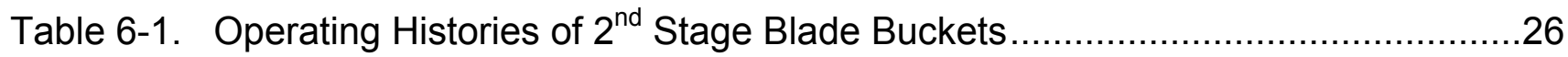

Table 6-2. Averaged Coating Thickness Measurements - Based on Two Measurements

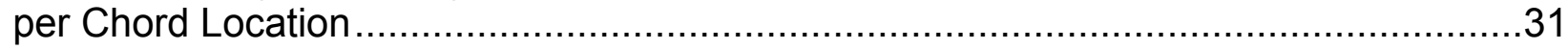

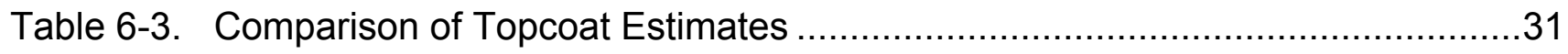

Table 6-4. Comparison of Combined Coating Thickness Estimates Based on Destructive Results to 3- and 4-layer Eddy Current Inversion Program Results .............................33

Table 6-5. Comparison of Wt\% Al Remaining to Eddy Current Conductivity Estimates......34

Table 6-6. Chemical Composition in Weight Percent from EDS......................................38

Table 7-1: Semi-quantitative chemical composition of coatings, wt $\%$...............................44 


\section{LIST OF FIGURES}

Figure 5-1: Condition of Coated Specimens after 12030 hours Exposure $1010^{\circ} \mathrm{C}\left(1850^{\circ} \mathrm{F}\right)$.

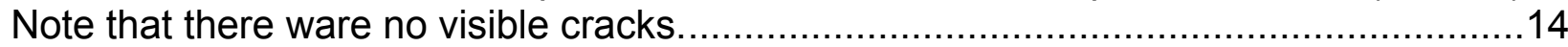

Figure 5-2: Photographs of coated specimens after exposure at $1038^{\circ} \mathrm{C}\left(1950^{\circ} \mathrm{F}\right)$............15

Figure 5-3 Optical micrographs showing variation of TGO thickness (a) after 1510 and b)

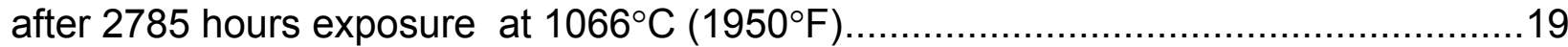

Figure 5-4 Optical micrographs showing variation of TGO thickness (a) after 1510 and b) after 2785 hours exposure at $1010^{\circ} \mathrm{C}\left(1850^{\circ} \mathrm{F}\right)$.

Figure 5-5. Comparison of computed and measured values of oxide thickness as a function of time of oxidation for three TBC systems: (1) APS TBC/NiCoCrAIY/GTD 111 DS, (b)

APS TBC/NiCoCrAIY/IN 738, and (c) APS TBC/NiCoCrAIY + Pt/IN 738.

Figure 5-6. Determination of the critical oxide thickness at TBC cracking for APS

TBC/NiCoCrAIY/GTD $111 \mathrm{DS}$. TBC cracking was observed after $5000 \mathrm{hrs}$ at $1038^{\circ} \mathrm{C}$ $\left(1900^{\circ} \mathrm{F}\right)$.

Figure 5-7. Computed TBC life diagram compared against experimental data for APS $\mathrm{TBC} / \mathrm{NiCoAIY/GTD} 111 \mathrm{DS}$ at $1066^{\circ} \mathrm{C}$.

Figure 5-8. Computed TBC life diagram compared against the experimental data of four

TBC systems at $1066^{\circ} \mathrm{C}\left(1950^{\circ} \mathrm{F}\right)$.

Figure 5-9. Comparison of computed TBC life boundaries against experimental data: (a) $1038^{\circ} \mathrm{C}\left(1900^{\circ} \mathrm{F}\right)$, and (b) $1010^{\circ} \mathrm{C}\left(1850^{\circ} \mathrm{F}\right)$.

Figure 5-10. Parameters of the TBC life boundary $\left(N_{s}=10^{a} \tau_{C}{ }^{b}\right)$ as a function of temperature: (a) parameter $a$, and (b) parameter $b$.

Figure 6-1. Details of the grid marks from the pressure and suction sides of the $2^{\text {nd }}$ stage bucket coated with GT 33+ coating.....

Figure 6-2. Suction Side of Blade 53 showing coating wear highlighted by the darker gray mark

Figure 6-3. Normalized Coil Impedance Plots from Sections E and O and a Composite Contour Plot of Normalized Impedance Plot from the Entire Suction Side.

Figure 6-4. Coating Profiles from Sections E and O at Respective Chord Locations Showing Presence of no Over-aluminized Topcoats 
Figure 6-5. Detail Coating Composition of Beta- and Gamma-Phase Found in Chord O2..32

Figure 6-6. Suction side of Blade 53 showing cut lines across Sections $F$ and $G$ and associated decrease in normalized coil impedance values 35

Figure 6-7. SEM photomicrographs of F4, F5, and F6 Transverse Sections.......................35

Figure 6-8. SEM Photomicrographs of G4, G7, and G8 Transverse Sections ...................37

Figure 7-1: Photograph of Blade 7 showing grids on the airfoil sections of Blades 7 and 57 where NDE measurements were taken. Note smaller squares on Blade 57.

Figure 7-2: Photographs showing metallurgical sample locations in Blade 7 and 57

Figure 7-3 Optical Microgrphs of sections of Blades 7 and 57 Showing TMF Cracks

Figure 7-4. Optical micrographs of coating on Blade 57 and 7 showing variation of aluminde/MCrAlY thickness and grit particle contamination at the coating/substrate interface. 


\section{COMBUSTION TURBINE (CT) HOT SECTION COATING LIFE MANAGEMENT}

\subsection{ABSTRACT}

The integrity of coatings used in hot section components of combustion turbines is crucial to the reliability of the buckets. This project was initiated in recognition of the need for predicting the life of coatings analytically, and non-destructively; correspondingly, three principal tasks were established. Task 1, with the objective of analytically developing stress, strain and temperature distributions in the bucket and thereby predicting thermal fatigue (TMF) damage for various operating conditions; Task 2 with the objective of developing eddy current techniques to measure both TMF damage and general degradation of coatings and, Task 3 with the objective of developing mechanism based algorithms. Task 4 would be aimed at verifying analytical predictions from Task 1 and the NDE predictions from Task 3 against field observations. Task 5 would develop a risk-based decision analysis model to make run/repair decisions. This report is a record of the progress to date on these four tasks. 


\subsection{INTRODUCTION}

The objective of this project is to improve the reliability, availability and maintainability (RAM) of combustion turbines (GTs) by developing advanced technology for assessing and managing the life of protective coatings on CT blades and vanes.

In recent years, gas turbines (GTs) have become the equipment of choice for power generation by both electric utilities and independent power producers. Continuing advances in design concepts and in structural materials and coatings for GT hot-section components have enabled increases in rotor inlet temperature resulting in major efficiency gains. These high temperatures mandate the use of coatings on hot section components (blades and vanes) to protect them from oxidation. Degradation of these protective coatings represents a major profitability challenge for turbine owners. Coating life usually dictates blade refurbishment intervals - which typically are shorter than desired for baseload units. Downtime for coating inspection and replenishment requires dispatch of less efficient generating equipment or purchase of replacement power. Coating failure can lead to rapid, severe damage to the superalloy substrate, warranting blade replacement. Replacement of a conventionally cast alloy blade row can cost up to $\$ 3$ million in the case of directionally solidified or single-crystal blades with internal cooling. Unavailability costs can run up to $\$ 500,000$ in lost revenues per day for a 500MW combined cycle plant. Blade failures can also cause downstream damage in the turbine, causing prolonged outages and revenue loss. Moreover, losses to electricity customers due to disruption in supply can also be very substantial. A proper life management system for coatings represents a major step in preventing such major losses to the GT owner and to society at large.

The life management activities covered in this project for coatings directly impacts the objectives of increasing RAM of GTs. Accurate life management techniques optimize refurbishment intervals and operating practices, thereby avoiding unplanned outages. Currently, coating refurbishment intervals are dictated by empirical, fleet-specific (rather than unit-specific) manufacturer recommendations based on the concept of "equivalent operating hours (EOH)." The new technology described in this proposal will enable machine-specific calculations of coating remaining life and direct measurements of the same using non-destructive evaluation (NDE) techniques.

The project is intended to develop improved analytical and nondestructive evaluation techniques to assess the consumed life and/or estimated life of protective coatings on CT blades and vanes, and then integrate these techniques with economic risk-based decisionanalysis tools to optimize run/repair/replace decisions. The project is defined along five major technical tasks including:

Task 1. Refinement and Validation of Hot Section Life Management Platform (HSLMP)

Task 2. COATLIFE for Advanced Metallic Coatings and TBCs

Task 3. NDE of Coatings

Task 4. Field Validation of COATLIFE and NDE

Task 5. Economic risk-based Decision Analysis (canceled) 
This report summarizes results from these tasks.

\subsection{EXECUTIVE SUMMARY}

The results of Task 1 were discussed in the previous semi-annual report for the period of April 1, 2003 through September 30, 2003 and will not be reviewed in the present semiannual report. It is important to note that a final technical progress report was completed for the Siemens-Westinghouse W501FC First Stage Blade Analysis and Transition Piece Durability (EPRI/DOE Report No. 1005049)—Issued December 2003.

The objective of Task 2 is to develop the capability of COATLIFE to handle spallation life prediction for TBCs that are being used in advanced turbines manufactured by major domestic OEMs and to enhance COATLIFE to cover broader range of MCrAIY coatings for oxidation life prediction. The MCrAIY coating selected for the evaluation was CT102. The chemical composition of the CT102 coating is similar to the nominal chemistry of GE's proprietary NiCoCrAlY coating GT33. The COATLIFE model treats coating degradation mechanisms that are applicable to TBC spallation, and bond coat degradation resulting from loss of aluminum. Isothermal oxidation tests at three temperatures are being conducted on TBC-coated GTD-111 and IN-738 specimens with two different bond coatings. Cyclic oxidation tests were conducted at two peak temperatures on the NiCoCrAlY coated and TBC coated specimens to determine the constants for COATLIFE model.

Isothermal oxidation tests at three different temperatures, $1010^{\circ} \mathrm{C}\left(1850^{\circ} \mathrm{F}\right), 1038^{\circ} \mathrm{C}$ $\left(1900^{\circ} \mathrm{F}\right)$, and $1066^{\circ} \mathrm{C}\left(1950^{\circ} \mathrm{F}\right)$ have been initiated on the TBC coated specimens. Testing at $1066^{\circ} \mathrm{C}\left(1950^{\circ} \mathrm{F}\right)$ was completed and cracking in TBC was observed in all the specimens exposed at this temperature. Cracks in TBC were found in three of the four specimens exposed to $1900^{\circ} \mathrm{F}\left(1038^{\circ} \mathrm{C}\right)$. The fourth-specimen has been exposed for about 10500 hours at $1038^{\circ} \mathrm{C}\left(1900^{\circ} \mathrm{F}\right)$. The TBC on all the specimens exposed at $1850^{\circ} \mathrm{F}\left(1010^{\circ} \mathrm{C}\right)$ was free from cracking after about 15000 hours exposure.

Cyclic oxidation testing of TBC coated specimens at the peak temperature of $1066^{\circ} \mathrm{C}$ $\left(1950^{\circ} \mathrm{F}\right)$ and $1010^{\circ} \mathrm{C}\left(1850^{\circ} \mathrm{F}\right)$ was completed. The results showed no significant difference in time to cracking among the four coating/substrate systems investigated. Consistent with this, variation of bond coating and substrate chemistries showed no affect on the kinetics of TGO growth among the four coating/substrate systems investigated. These results are used to obtain the constants for the TBC life model. A 24- hour hold time testing at the peak temperature of $1066^{\circ} \mathrm{C}\left(1950^{\circ} \mathrm{F}\right)$ was initiated and completed and these results are used to validate the TBC life model.

Considering the physical degradation mechanisms, a mechanistic model has been developed for predicting remaining service lives of TBCs. The predictive capabilities of the model are demonstrated by comparing the model predictions against the results published in the literature for APS TBCs. The model was validated using the 24-hour hold time data. 
These results indicated that the model predictions were in good agreement with the experimental data.

The objective of Task 3 is to develop inspection technologies sufficient to quantitatively evaluate degradation of service-exposed (and degraded) coatings. Buckets exhibiting various levels of degradation have been acquired for development of the inspection criteria and for destructive analysis. In this task, a state-of-the-art F-SECT inspection system has been assembled to test and evaluate both duplex and simplex metallic coatings of the 7FA and the 9FA blade buckets. The assembled F-SECT system demonstrated its capability to provide both qualitative and quantitative information about coating conditions.

Capability of the F-SECT inspection system to detect, discriminate, and characterize such coating conditions as normal coating, $\beta$-phase depletion, and cracked coating was already demonstrated and reported previously. In addition, it was possible based on the built-in inversion program to estimate coating layer thickness vales and the associated conductivity values of NiCoCrAIY bond coat and GTD-111 substrate from service-aged 7FA second stage bucket with GT 33+ coatings. When topcoats are completely depleted, however, no reliable estimates of the topcoat thickness values were obtained. Thus, it was necessary to evaluate the combined topcoat and bond coat thickness value instead of the individual coating layers. By focusing on the total coating thickness, more accurate overall coating thickness values were obtained.

Additional testing showed that F-SECT system is capable of assessing a service-aged bucket coated with CoCrAlY simple coating (GT 29). Due to heavy oxidation of CoCrAlY coating accompanied by diffusion of aluminum into the substrate as columnar AIN and finely dispersed TiN precipitates, no effective base metal protection was provided, especially, at $50 \%$ of the blade height location. In addition to the loss of coating protection, chromium depletion caused the GT29 coating to become magnetic. The magnetic characteristic of the coating was identified from the unique hook-pattern impedance plot obtained at low frequency. By reviewing the normalized coil impedance plots over frequency, it was possible to detect and discriminate $\beta$-phase depletion of coating from the base metal corrosion. Due to lack of normal coatings found on the evaluated bucket, no quantitative analysis was possible.

Individual cutout sections can be evaluated using plots of normalized impedance versus frequency or normalized impedance versus chord position. In general, normal coating/substrate conditions present highest normalized impedance curves with positive slopes, followed next by almost flat curves representing $\beta$-phase depletion, and finally curves with negatives slopes representing the presence of crazed cracking and possible corrosion of base metal. To review the entire airfoil condition, a colored contour map of normalized impedance values was plotted to show the affected area of interest. In general, more degradation on the suction side was noted at the leading edge of the blade surface.

During this reporting period, considerable progress has been made in the data display presentation by plotting colored contour maps of those calculated parameters, such as normalized impedance values, conductivity values, and coating thickness values. By 
reviewing the colored contour map of the entire bucket, it was easier to locate the problem areas associated with coating degradation. The colored contour maps showed general agreement of higher normalized impedance values to higher conductivity values. Also, higher $\sigma$ values correlated better with wt.\% of remaining aluminum than the area fraction of $\beta$-phase particles remaining. The progress made to date combined with other on-going efforts will hopefully result in generating a calibration curve that would correlate $\sigma$ of coatings to wt. \% of aluminum remaining in the topcoat or combined topcoat/bond coat layer. The estimated wt.\% of aluminum remaining can then be used as input to COATLIFE to assess the remaining useful coat life.

The objective of Task 4 is to validate the predictive capabilities of COATLIFE and the eddy current NDE methodologies (developed in Task 2 and 3 respectively) on service-exposed buckets. Following NDE evaluation, two service-run GE Frame 7FA blades (\# 7 and 57) were received for metallurgical evaluation. Blade 7 and 57 had seen 8286 hours of operation with 670 start-stop cycles and 2000 hours of operation with 219 start-stop cycles, respectively. The blades had GT 33 plus, over aluminized NiCoCrAlY coating. For NDE validation, three transverse sections at the $25 \%, 50 \%$, and $75 \%$ blade height locations were removed from each blade and several metallurgical mounts were prepared from all these sections and examined in optical microscope and SEM for determining the location and the extent of TMF cracking, coating degradation at various locations on the blades. The reaming aluminum content in the coating at various locations of the mounts was also determined. These results need to be correlated with NDE measurements.

The metallurgical examinations showed that Blade 57 was more severely cracked than Blade 7. Blade 7 had an uniform top aluminde (0.002 inch thick) layer and MCrAlY coating on the convex and concave sides of the airfoil. On the other hand, the coating thickness on Blade 57 was found to vary from location to location. It had a three to four mil thick aluminide top coating. In addition, the MCrAlY/substrate interface was contaminated with grit particles. The aluminum content in the MCrAlY coating on Blade 57 was significantly higher than that of the coating on Blade 7. Thicker aluminide coating and the higher aluminum content in the MCrAlY coating on Blade 57 were presumably responsible for extensive TMF cracking.

Task 5 was canceled per agreement with DOE. 


\subsection{TASK 1: REFINEMENT AND VALIDATION OF HSLMP}

The results of Task 1 were discussed in the previous semi-annual report for the period of April 1, 2003 through September 30, 2003 and will not be reviewed in the present semiannual report. It is important to note that a final technical progress report was completed for the Siemens-Westinghouse W501FC First Stage Blade Analysis and Transition Piece Durability (EPRI/DOE Report No. 1005049)—Issued December 2003.

\subsection{TASK 2: COATLIFE FOR ADVANCED METALLIC COATINGS AND TBCS}

\subsection{Task 2.1 Thermal Barrier Coatings}

\subsection{A Experimental Procedures}

\section{Materials and Coatings}

Three shank sections of GTD-111 DS blades and three shank sections of IN-738 blades retired from Frame 5002 engines were procured for machining test coupons. The shank sections operate at a much lower temperature than the airfoil section of a blade and, as a result, the material at the shank section is not expected to degrade during service. The structure and properties of the material at the shank section represent the initial, as heat-treated condition.

Compositional measurements were made at selected locations on the GTD-111 and IN-738 blade shank sections using energy dispersive X-ray spectroscopy (EDS). The composition of the blade materials is given in Table 5-1.

Table 5-1. Chemical composition of GTD-111 and IN-738 test materials (wt. \%).

\begin{tabular}{|l|c|c|c|c|c|c|c|c|c|}
\hline Blade & $\mathrm{Al}$ & $\mathrm{Ti}$ & $\mathrm{Cr}$ & $\mathrm{Co}$ & $\mathrm{Mo}$ & $\mathrm{Nb}$ & $\mathrm{Ta}$ & $\mathrm{W}$ & $\mathrm{Ni}$ \\
\hline GTD-111 & 3.2 & 5.2 & 14.4 & 9.2 & 2.1 & - & 4.0 & 3.2 & $\mathrm{Bal}$ \\
\hline IN-738 & 3.8 & 3.6 & 16.0 & 8.3 & 1.9 & 1.1 & 2.1 & 2.2 & $\mathrm{Bal}$ \\
\hline
\end{tabular}

About 150 cylindrical specimens (0.36 inch diameter and 1.5 inches long) were removed from the GTD-111 and IN-738 blade shank sections using an electro-discharge machining process. The specimens were ground and polished to remove the recast layer. Turbine Airfoils, Coatings, and Repairs (TACR) applied bond and yttria stabilized zirconia coatings. A low-pressure plasma spray process (LPPS) was used to apply NiCoCrAIY (CT102) coating to all specimens. The composition of the powder is given in Table 5-2. The composition of the powder is comparable to the nominal chemistry of GE's proprietary coating GT33. After application of the coating all specimens were given a vacuum diffusion treatment at $1121^{\circ} \mathrm{C}\left(2050^{\circ} \mathrm{F}\right)$ for two hours. An approximately $10 \mu \mathrm{m}$ thick layer of platinum was applied by electroplating on half of the NiCoCrAIY coated specimens. The Pt plated NiCoCrAIY was selected because Siemens Westinghouse uses the platinum-plated CT102 as a bond coating for TBC-coated parts of advanced turbines. Following electroplating, the specimens were given a vacuum diffusion heat treatment at $1121^{\circ} \mathrm{C}\left(2050^{\circ} \mathrm{F}\right)$ for two hours. All CT102 and platinum-plated CT102 specimens were then given an aging treatment at $843^{\circ} \mathrm{C}$ $\left(1550^{\circ} \mathrm{F}\right)$ for 24 hours prior to the application of the top ceramic coating, a standard yttria stabilized 
zirconia, by using an air plasma spray (APS) process. The chemical composition of the ceramic coating powder is given in Table 5-3.

Table 5-2. Chemical composition of CT102 bond coating powder (wt\%).

\begin{tabular}{|c|c|c|c|c|}
\hline $\mathbf{A l}$ & Co & $\mathbf{C r}$ & $\mathbf{N i}$ & $\mathbf{Y}$ \\
\hline 8.0 & Balance & 21.0 & 32.0 & 0.5 \\
\hline
\end{tabular}

Table 5-3. Chemical composition of ceramic coating powder (wt.\%).

\begin{tabular}{|c|c|c|c|c|c|c|}
\hline $\mathbf{A l}_{\mathbf{2}} \mathbf{O}_{3}$ & $\mathrm{Fe}_{\mathbf{2}} \mathbf{O}_{3}$ & $\mathbf{S i O}_{2}$ & $\mathbf{T i O}_{\mathbf{2}}$ & $\mathbf{Y}_{\mathbf{2}} \mathbf{O}_{3}$ & $\mathbf{H f O}_{\mathbf{2}}$ & $\mathbf{Z r O}_{\mathbf{2}}$ \\
\hline 0.13 & 0.02 & 0.27 & 0.09 & 7.69 & 1.85 & Balance \\
\hline
\end{tabular}

\section{Isothermal Tests}

Multiple TBC-coated GTD-111 and IN-738 specimens with two different bond coatings are aged in three different furnaces, which are maintained at three temperatures: $1010^{\circ} \mathrm{C}\left(1850^{\circ} \mathrm{F}\right), 1038^{\circ} \mathrm{C}$ $\left(1900^{\circ} \mathrm{F}\right)$, and $1066^{\circ} \mathrm{C}\left(1950^{\circ} \mathrm{F}\right)$. One specimen from each substrate/coating system is removed at predetermined intervals for metallurgical evaluation.

\section{Cyclic Exposure Tests}

Cyclic exposure testing of coated specimens was conducted at two peak temperatures of $1066^{\circ} \mathrm{C}$ $\left(1950^{\circ} \mathrm{F}\right)$ and $1010^{\circ} \mathrm{C}\left(1850^{\circ} \mathrm{F}\right)$. The coated specimens were cycled between the peak and room temperatures. The thermal cycle consisted of holding the specimens at the peak temperature for 55 minutes and then air cooled for five minutes. Tests were also conducted at the peak temperature of $1066^{\circ} \mathrm{C}\left(1950^{\circ} \mathrm{F}\right)$.

\subsection{B Results and Discussions}

\section{Isothermal Exposure Testing}

Isothermal Exposure Testing at $1066^{\circ} \mathrm{C}\left(1950^{\circ} \mathrm{F}\right)$ was completed. Testing at the other two temperatures, $1038^{\circ} \mathrm{C}\left(1900^{\circ} \mathrm{F}\right)$ and $1010^{\circ} \mathrm{C}\left(1850^{\circ} \mathrm{F}\right)$ has been in progress. The specimens have been exposed for about 10,500 hours at $1038^{\circ} \mathrm{C}\left(1900^{\circ} \mathrm{F}\right)$ and 15,500 hours at $1010^{\circ} \mathrm{C}\left(1850^{\circ} \mathrm{F}\right)$ to date, respectively. Cracks in TBC were found in three of the four specimens exposed to $1038^{\circ} \mathrm{C}$ $\left(1900^{\circ} \mathrm{F}\right)$. The $\mathrm{TBC}$ on all specimens exposed at $1010^{\circ} \mathrm{C}\left(1850^{\circ} \mathrm{F}\right)$ was free from cracking. Condition of the specimens after 12030 hours exposure at $1010^{\circ} \mathrm{C}\left(1850^{\circ} \mathrm{F}\right)$ is shown in Figure 1. Time to crack TBC for different coating/substrate systems is given in Table 3 . The results show that under isothermal conditions, the TBC on platinum plated MCrAlY coated specimens exhibited 
slightly longer life. Typical morphology of cracking or spallation of the TBC on the specimens are illustrated in Figure 5-2

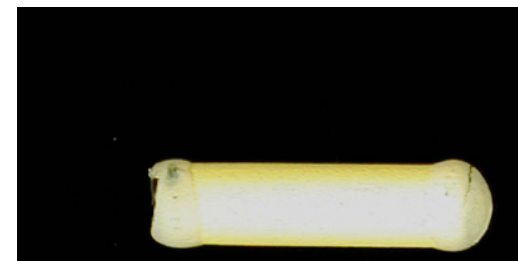

\#1

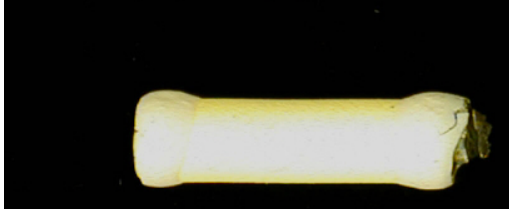

\#3
\#2

\section{\#4}

Figure 5-1: Condition of Coated Specimens after 12030 hours Exposure $1010^{\circ} \mathrm{C}\left(1850^{\circ} \mathrm{F}\right)$. Note that there ware no visible cracks.

Table 5-4: Time for TBC cracking or Spallation after Isothermal Exposure

\begin{tabular}{|c|c|c|c|c|}
\hline System ID & Base Metal & Bond Coating & Temperature & Time to Crack or Spall, hours \\
\hline 1 & GTD 111 & NiCoCrAlY & $1066^{\circ} \mathrm{C}\left(1950^{\circ} \mathrm{F}\right)$ & \multirow{9}{*}{ Proprietary Information } \\
\hline 2 & IN 738 & NiCoCrAlY & $1066^{\circ} \mathrm{C}\left(1950^{\circ} \mathrm{F}\right)$ & \\
\hline 2 & IN 738 & NiCoCrAlY & $1066^{\circ} \mathrm{C}\left(1950^{\circ} \mathrm{F}\right)$ & \\
\hline 3 & GTD 111 & $\mathrm{NiCoCrAIY+Pt}$ & $1066^{\circ} \mathrm{C}\left(1950^{\circ} \mathrm{F}\right)$ & \\
\hline 4 & IN 738 & $\mathrm{NiCoCrAIY+Pt}$ & $1066^{\circ} \mathrm{C}\left(1950^{\circ} \mathrm{F}\right)$ & \\
\hline 1 & GTD 111 & NiCoCrAlY & $1038^{\circ} \mathrm{C}\left(1900^{\circ} \mathrm{F}\right)$ & \\
\hline 2 & IN 738 & NiCoCrAlY & $1038^{\circ} \mathrm{C}\left(1900^{\circ} \mathrm{F}\right)$ & \\
\hline 3 & GTD 111 & $\mathrm{NiCoCrAlY}+\mathrm{Pt}$ & $1038^{\circ} \mathrm{C}\left(1900^{\circ} \mathrm{F}\right)$ & \\
\hline 4 & IN 738 & NiCoCrAlY+Pt & $1038^{\circ} \mathrm{C}\left(1900^{\circ} \mathrm{F}\right)$ & \\
\hline
\end{tabular}



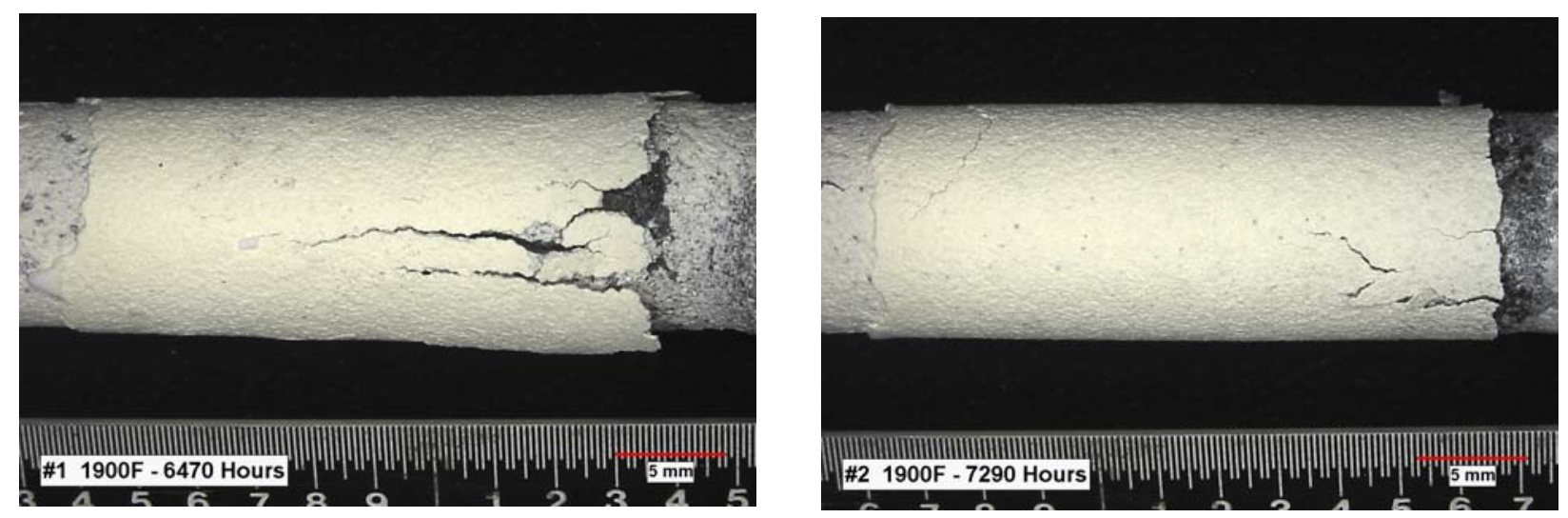

Figure 5-2: Photographs of coated specimens after exposure at $1038^{\circ} \mathrm{C}\left(1950^{\circ} \mathrm{F}\right)$.

\section{Cyclic Exposure Testing}

Cyclic exposure testing of the TBC-coated specimens at the peak temperatures of $1066^{\circ} \mathrm{C}\left(1950^{\circ} \mathrm{F}\right)$ and $1010^{\circ} \mathrm{C}\left(1850^{\circ} \mathrm{F}\right)$ was completed. Time to cracking of TBC on different bond coating/substrate systems is presented in Table 5-1. Considering the scatter in the test results, the results showed no significant difference in time to cracking among the four coating/substrate systems investigated. These results are used to obtain the constants for the TBC life model.

Table 5-5: Thermal cycling between $1066^{\circ} \mathrm{C}\left(1950^{\circ} \mathrm{F}\right)$ and room temperature test results

\begin{tabular}{|c|c|c|c|}
\hline System ID & Base Metal & Bond Coating & Cycles to Crack or Spall TBC \\
\hline $1-1$ & GTD 111 & NiCoCrAlY & \multirow{11}{*}{ Proprietary Information } \\
\hline $1-2$ & GTD 111 & NiCoCrAlY & \\
\hline $1-3$ & GTD 111 & NiCoCrAlY & \\
\hline $2-1$ & IN 738 & NiCoCrAlY & \\
\hline $2-2$ & IN 738 & NiCoCrAlY & \\
\hline $2-3$ & IN 738 & NiCoCrAlY & \\
\hline $3-1$ & GTD 111 & $\mathrm{NiCoCrAIY+Pt}$ & \\
\hline $3-2$ & GTD 111 & $\mathrm{NiCoCrAlY+Pt}$ & \\
\hline $3-3$ & GTD 111 & $\mathrm{NiCoCrAIY+Pt}$ & \\
\hline $4-1$ & IN 738 & $\mathrm{NiCoCrAIY+Pt}$ & \\
\hline $4-2$ & IN 738 & $\mathrm{NiCoCrAlY+Pt}$ & \\
\hline
\end{tabular}


Table 5-6: Thermal cycling between $1010^{\circ} \mathrm{C}\left(1850^{\circ} \mathrm{F}\right)$ and room temperature test results

\begin{tabular}{|c|c|c|c|}
\hline System ID & Base Metal & Bond Coating & Cycles to Crack or Spall TBC \\
\hline $1-1$ & GTD 111 & NiCoCrAlY & \multirow{12}{*}{ Proprietary Information } \\
\hline $1-2$ & GTD 111 & NiCoCrAlY & \\
\hline $1-3$ & GTD 111 & NiCoCrAlY & \\
\hline $2-1$ & IN 738 & NiCoCrAlY & \\
\hline $2-2$ & IN 738 & NiCoCrAlY & \\
\hline $2-3$ & IN 738 & NiCoCrAlY & \\
\hline 3-1 & GTD 111 & $\mathrm{NiCoCrAlY+Pt}$ & \\
\hline $3-2$ & GTD 111 & $\mathrm{NiCoCrAlY+Pt}$ & \\
\hline $3-3$ & GTD 111 & $\mathrm{NiCoCrAlY+Pt}$ & \\
\hline $4-1$ & IN 738 & $\mathrm{NiCoCrAlY+Pt}$ & \\
\hline $4-2$ & IN 738 & $\mathrm{NiCoCrAlY}+\mathrm{Pt}$ & \\
\hline $4-3$ & IN 738 & $\mathrm{NiCoCrAlY+Pt}$ & \\
\hline
\end{tabular}

Cyclic exposure testing with 24 hours hold time at the peak temperature of $1066^{\circ} \mathrm{C}\left(1950^{\circ} \mathrm{F}\right)$ was also completed. Cycle to cracking TBC varied from 65 to 110 cycles among the four bond coating/base metal systems, as shown in Table 5-6. These results are used to validate the TBC life model.

Table 5-7: Thermal cycling test results at the peak temperature of $1038^{\circ} \mathrm{C} 1900^{\circ} \mathrm{F}$ ) with 24 hour hold time.

\begin{tabular}{|c|c|c|c|}
\hline System ID & Base Metal & Bond Coating & Time to Crack or Spall TBC, cycles \\
\hline 1 & GTD 111 & NiCoCrAIY & \multirow{4}{*}{ Proprietary Information } \\
\hline 2 & IN 738 & NiCoCrAlY & \\
\hline 3 & GTD 111 & $\mathrm{NiCoCrAIY+Pt}$ & \\
\hline 4 & IN 738 & $\mathrm{NiCoCrAIY+Pt}$ & \\
\hline
\end{tabular}

\section{Microstructure Of Exposed Specimens}

Metallurgical mounts were prepared from the samples removed after isothermal exposure at $1010^{\circ} \mathrm{C}$ $\left(1850^{\circ} \mathrm{F}\right), 1038^{\circ} \mathrm{C}\left(1900^{\circ} \mathrm{F}\right)$, and $1066^{\circ} \mathrm{C}\left(1950^{\circ} \mathrm{F}\right)$ for different times to determine the variation of coating degradation and the TGO thickness among the four coating systems. The preliminary examinations showed that the presence of Pt interlayer between the MCrAIY and the TBC on both GTD-111 and IN-738 base materials did not show any effect on the TGO thickness. Based on this observation, TGO thickness was measured as a function of exposure time for three of the four coating systems. On each sample about 30 to 50 measurements were taken and the average TGO scale thickness as a function of time and temperature is summarized Table 7. The TGO thickness measurements exhibited a large scatter. No significant variation in the TGO thickness was seen among these systems. The TGO thickness on the IN-738 specimens with and without a Pt-interlayer was comparable. These observations indicate that the base material and bond coating chemistries have no significant affect on the kinetics of TGO growth. 
Typical morphology of the TGO scale is shown in Figures 5-3 and 5-4. It can be seen from the results that the TGO scale thickness increased with exposure time and temperature. These results are used to generate the constants for the TBC life model. 
Table 5-8: Influence of exposure temperature and time on thermally grown oxide (TGO) scale thickness on TBC coated specimens

\begin{tabular}{|c|c|c|c|c|c|}
\hline SYSTEM ID & $\begin{array}{l}\text { BASE } \\
\text { MATERIAL }\end{array}$ & BOND COATING & $\begin{array}{l}\text { EXP. TEMP } \\
{ }^{\circ} \mathrm{C}\left({ }^{\circ} \mathrm{F}\right)\end{array}$ & $\begin{array}{l}\text { EXP. TIME } \\
\text { HOURS }\end{array}$ & \begin{tabular}{|l} 
AVE. TGO \\
THICKNESS, \\
MM \\
\end{tabular} \\
\hline \multirow[t]{13}{*}{1} & GTD-111 & NICOCRALY & $1066(1950)$ & 1005 & \multirow{39}{*}{$\begin{array}{l}\text { PROPRIETARY } \\
\text { INFORMATION }\end{array}$} \\
\hline & & & & 1510 & \\
\hline & & & & 2025 & \\
\hline & & & & 2785 & \\
\hline & & & & 2925 & \\
\hline & & & $1038(1900)$ & 1005 & \\
\hline & & & & 2015 & \\
\hline & & & & 4510 & \\
\hline & & & $1010(1850)$ & 2015 & \\
\hline & & & & 5015 & \\
\hline & & & & 8155 & \\
\hline & & & & 9850 & \\
\hline & & & & 12030 & \\
\hline \multirow[t]{13}{*}{2} & IN-738 & NICOCRALY & $1066(1950)$ & 1005 & \\
\hline & & & & 1510 & \\
\hline & & & & 2025 & \\
\hline & & & & 2785 & \\
\hline & & & & 2925 & \\
\hline & & & $1038(1900)$ & 1005 & \\
\hline & & & & 2015 & \\
\hline & & & & 4510 & \\
\hline & & & $1010(1850)$ & 2015 & \\
\hline & & & & 5015 & \\
\hline & & & & 8155 & \\
\hline & & & & 9850 & \\
\hline & & & & 12030 & \\
\hline \multirow[t]{13}{*}{4} & IN-738 & NICOCRALY+PT & 1066(1950) & 1005 & \\
\hline & & & & 1510 & \\
\hline & & & & 2025 & \\
\hline & & & & 2785 & \\
\hline & & & & 2925 & \\
\hline & & & $1038(1900)$ & 1005 & \\
\hline & & & & 2015 & \\
\hline & & & & 4510 & \\
\hline & & & $1010(1850)$ & 2015 & \\
\hline & & & & 5015 & \\
\hline & & & & 8155 & \\
\hline & & & & 9850 & \\
\hline & & & & 12030 & \\
\hline
\end{tabular}



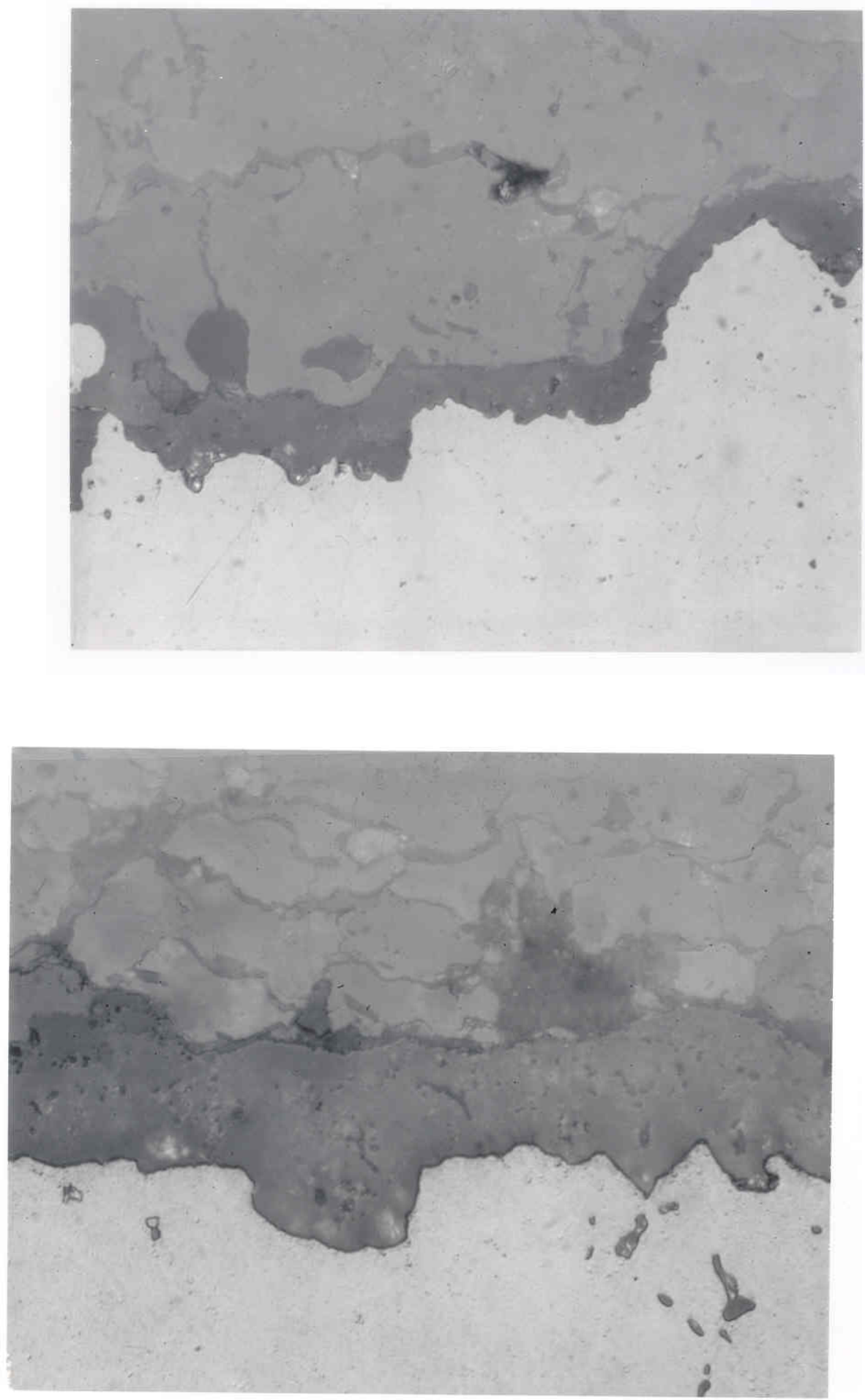

Figure 5-3 Optical micrographs showing variation of TGO thickness (a) after 1510 and b) after 2785 hours exposure at $1066^{\circ} \mathrm{C}\left(1950^{\circ} \mathrm{F}\right)$ 

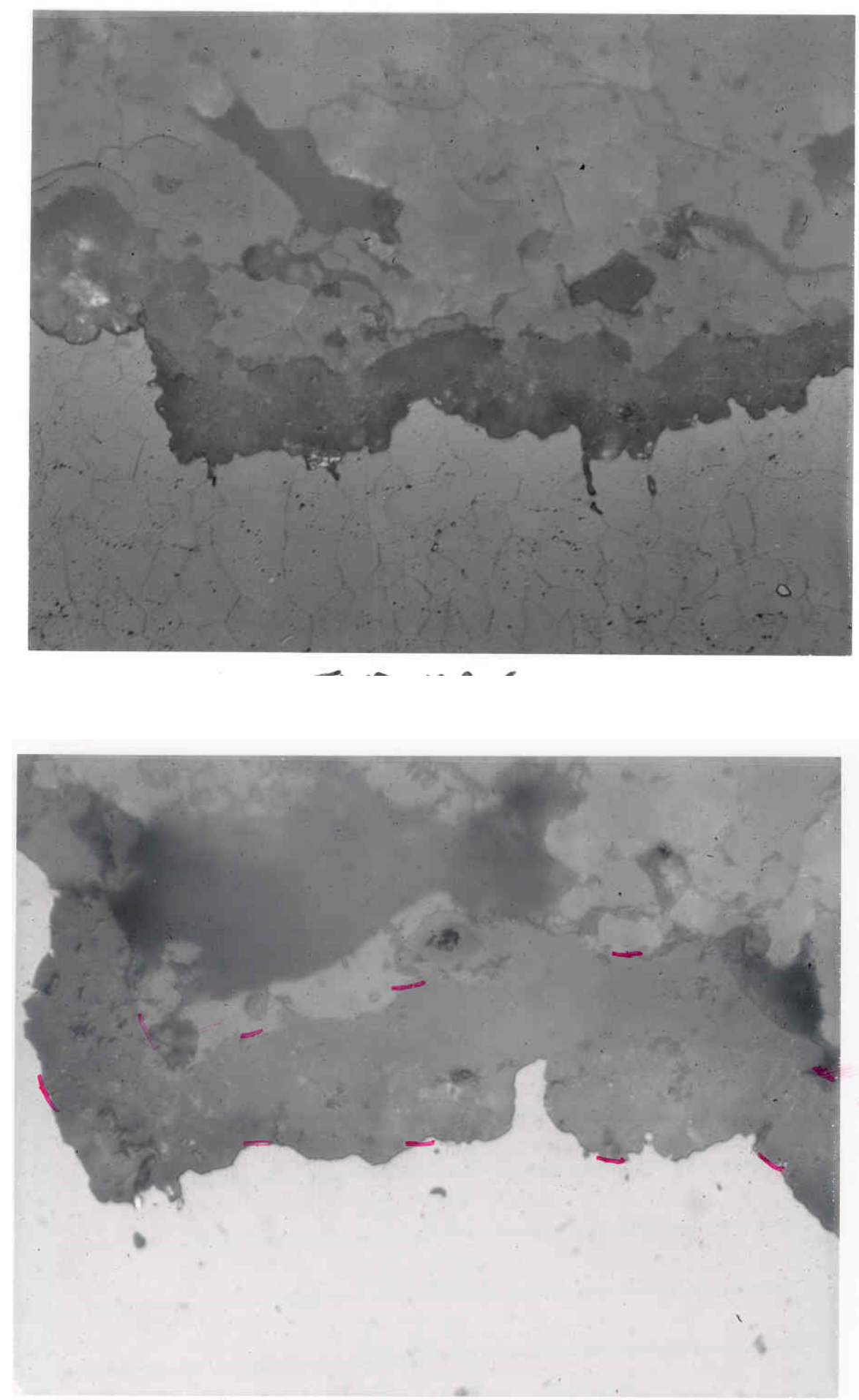

Figure 5-4 Optical micrographs showing variation of TGO thickness (a) after 1510 and b) after 2785 hours exposure at $1010^{\circ} \mathrm{C}\left(1850^{\circ} \mathrm{F}\right)$ 


\subsection{TBC Life Algorithm Development}

The oxidation kinetics of the APS TBC/NiCoCrAlY bond coat with or without Pt interlayer addition on GTD 111 DS and IN 718 substrates were characterized and compared. In all cases, a parabolic rate equation was used to describe the TGO thickness, $\delta$, as a function of time, $t$, of thermal exposure. The parabolic rate constant, $k_{p}$, was obtained by plotting the TGO thickness as a function of $t^{1 / 2}$; linear regression of the experimental data provided the value of the parabolic rate constant, $\mathrm{k}_{\mathrm{p}}$, at a given temperature, T. Comparison of the calculated and measured oxide thickness indicated that all four coating systems examined in this study exhibited very similar bond coat oxidation kinetics, regardless of the substrate and the addition of Pt in the bond coat. Figure 5 (a), (b), and (c) present the computed and observed oxide thickness as a function of time of oxidation for APS TBC on NiCoCrAIY/GTD 111DS, NiCoCrAIY/IN 738, and on NiCoCrAIY + Pt/IN738 systems at $1066^{\circ} \mathrm{C}$ $\left(1950^{\circ} \mathrm{F}\right)$, respectively. The results indicated that in all coating systems, oxidation is well described by a parabolic rate equation with an identical value of $\mathrm{k}_{\mathrm{p}}$. Similar results were obtained for these coatings tested at $1010^{\circ} \mathrm{C}\left(1850^{\circ} \mathrm{F}\right)$ also. Based on the time to internal oxidation (Figure 5(b)) and the time to TBC cracking (Figure 6), the critical TGO thickness at TBC failure was determined to be about $20 \mu \mathrm{m}$ for all four coating systems examined in this project.

The oxidation kinetic constants and the critical TGO thickness were utilized in conjunction with the TBC life model to compute the number of start-up cycles (TBC life) as a function of cycle time.

Figure 7 shows a comparison of the calculated and measured TBC lives for APS TBC/NiCoCrAIY/GTD $111 \mathrm{DS}$ tested at a peak temperature of $1066^{\circ} \mathrm{C}\left(1950^{\circ} \mathrm{F}\right)$, which shows excellent agreement between model calculation and experimental data. Experimental data at one-hour cycle time and one start-up cycle (isothermal oxidation data) were both used to evaluate material constants in the TBC life model. The excellent agreement at both ends of the TBC life boundary was thus due to fitting of the model to the experimental data. On the other hand, the excellent agreement between model calculation and the experimental data for 24-hour cycle time represented an independent prediction since the experimental data was not used to calibrate the model and the prediction was made before the experiment was conducted.

Figure 8 shows a comparison of the predicted and measured TBC lives for all four TBC systems at $1066^{\circ} \mathrm{C}$. All four coating systems were predicted to exhibit essentially identical TBC lives because of similar bond coating oxidation kinetics, as predicted by the TBC life model. Figure 8 also present a linear approximation of the TBC life boundary that is used to develop TBC life diagrams for incorporation into COATLIFE.

The TBC model was also used to predict the coating life diagrams for various temperatures ranging from for $1038^{\circ} \mathrm{C}\left(1900^{\circ} \mathrm{F}\right)$ to $816^{\circ} \mathrm{C}\left(1500^{\circ} \mathrm{F}\right)$ at $27.8^{\circ} \mathrm{C}\left(50^{\circ} \mathrm{F}\right)$ increments. Figure $9(\mathrm{a})$ and (b) show comparison of predicted and measured TBC lives for $1038^{\circ} \mathrm{C}$ and $1010^{\circ} \mathrm{C}$, respectively, together with the corresponding linear approximations for implementation into COATLIFE.

For incorporation into COATLIFE, the linear approximations of the TBC life boundaries were described in term of a two-parameter expression given by

$$
N_{S}=10^{a} \tau_{C}^{b}
$$


where $N_{s}$ is TBC life (i.e., number of start up cycles), $\tau_{c}$ is the cycle time, $a$ and $b$ are temperaturedependent constants derived from the TBC life diagrams computed via the TBC life model for various temperatures. Plots of $a$ and $b$ as a function of temperature are shown in Figures 10(a) and (b), respectively. As shown in Figure 5-10, the values of $a$ and $b$ both decrease linearly with increasing temperatures.

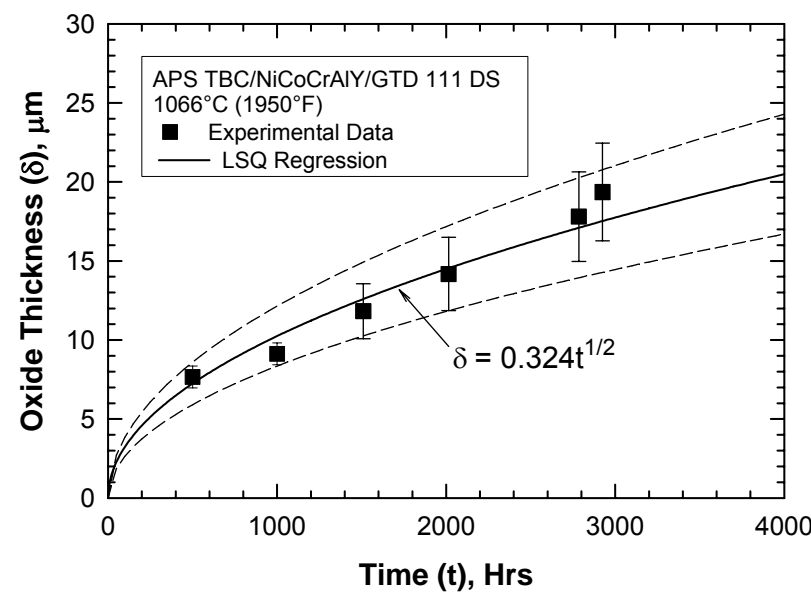

(a)

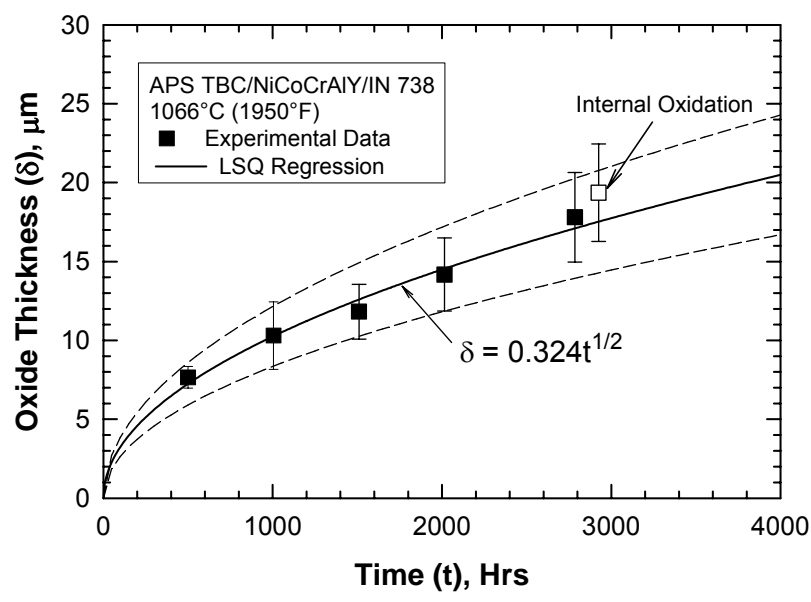

(b)

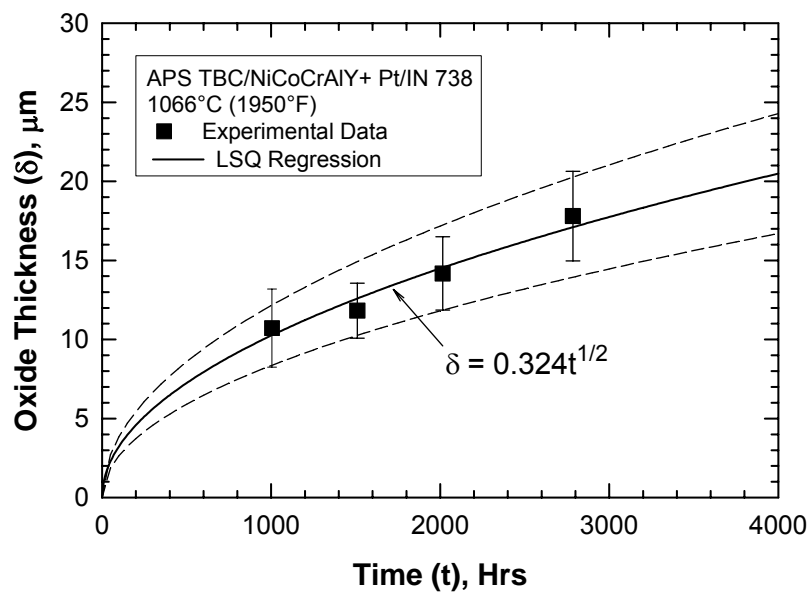

(c)

Figure 5-5. Comparison of computed and measured values of oxide thickness as a function of time of oxidation for three TBC systems: (1) APS TBC/NiCoCrAIY/GTD 111 DS, (b) APS TBC/NiCoCrAIY/IN 738, and (c) APS TBC/NiCoCrAIY + Pt/IN 738. 


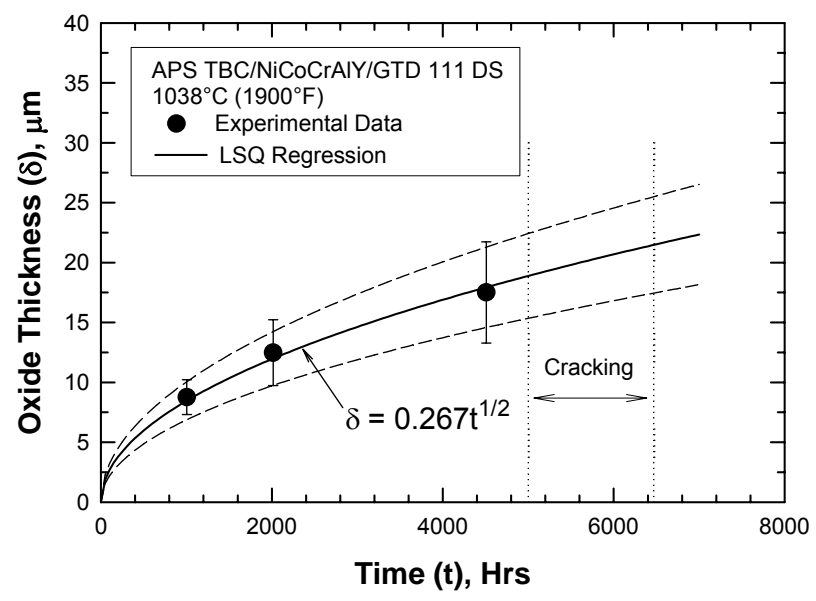

Figure 5-6. Determination of the critical oxide thickness at TBC cracking for APS TBC/NiCoCrAIY/GTD 111 DS. TBC cracking was observed after $5000 \mathrm{hrs}$ at $1038^{\circ} \mathrm{C}\left(1900^{\circ} \mathrm{F}\right)$.

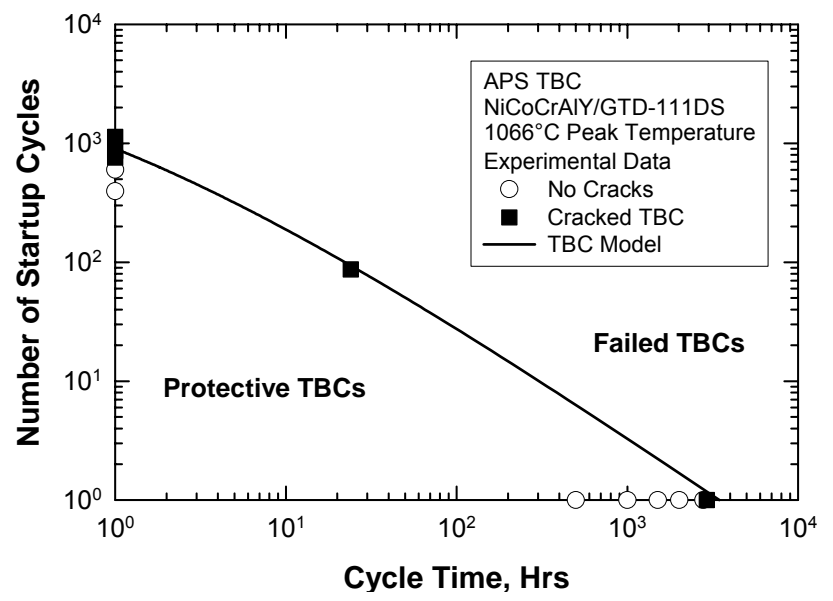

Figure 5-7. Computed TBC life diagram compared against experimental data for APS TBC/NiCoAIYIGTD $111 \mathrm{DS}$ at $1066^{\circ} \mathrm{C}$. 


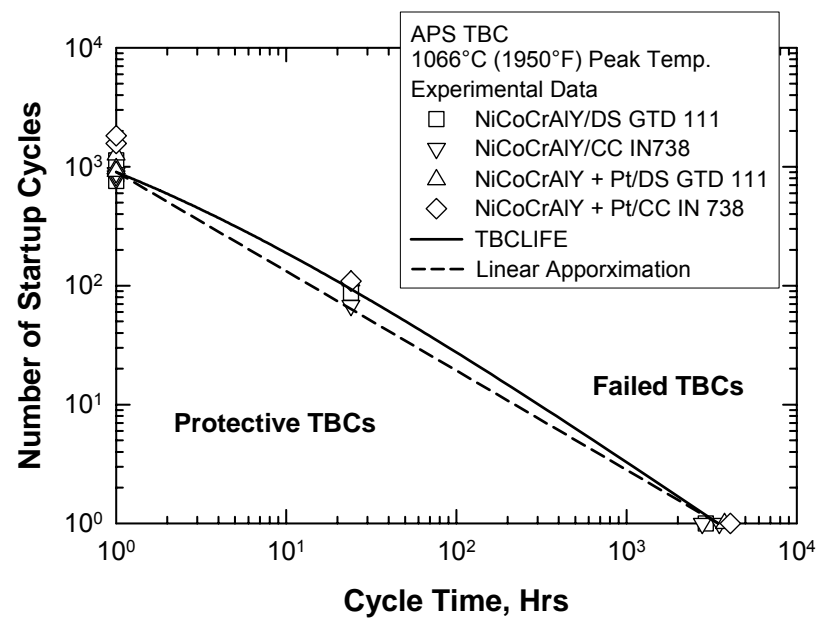

Figure 5-8. Computed TBC life diagram compared against the experimental data of four TBC systems at $1066^{\circ} \mathrm{C}\left(1950^{\circ} \mathrm{F}\right)$.

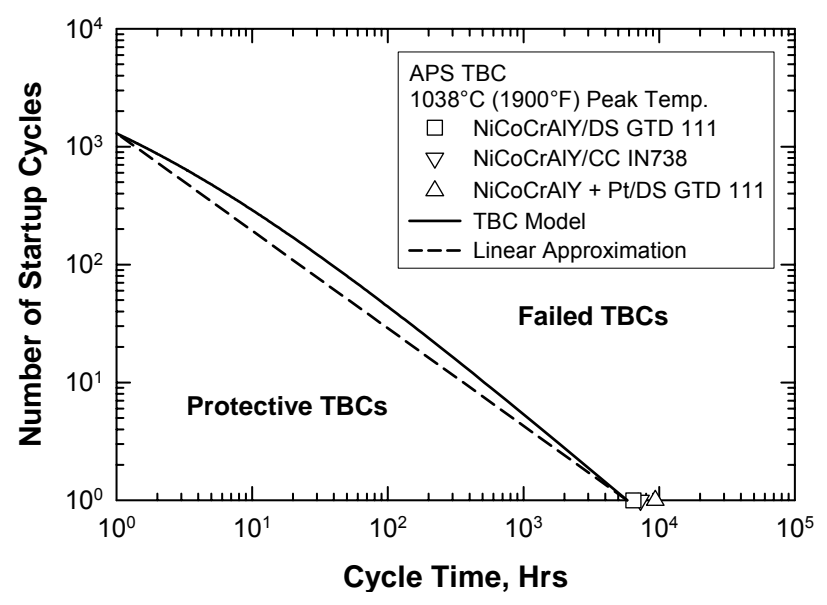

(a)

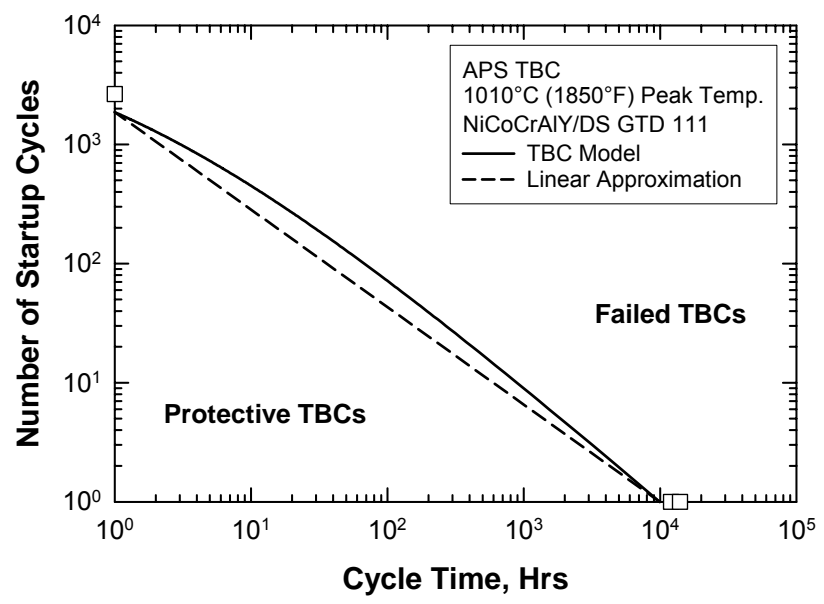

(b)

Figure 5-9. Comparison of computed TBC life boundaries against experimental data: (a) $1038^{\circ} \mathrm{C}$ $\left(1900^{\circ} \mathrm{F}\right)$, and (b) $1010^{\circ} \mathrm{C}\left(1850^{\circ} \mathrm{F}\right)$. 


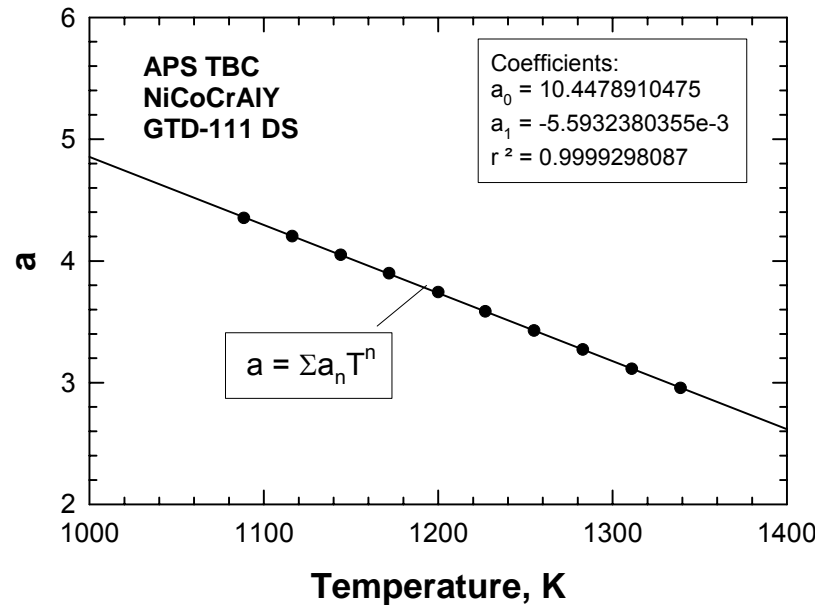

(a)

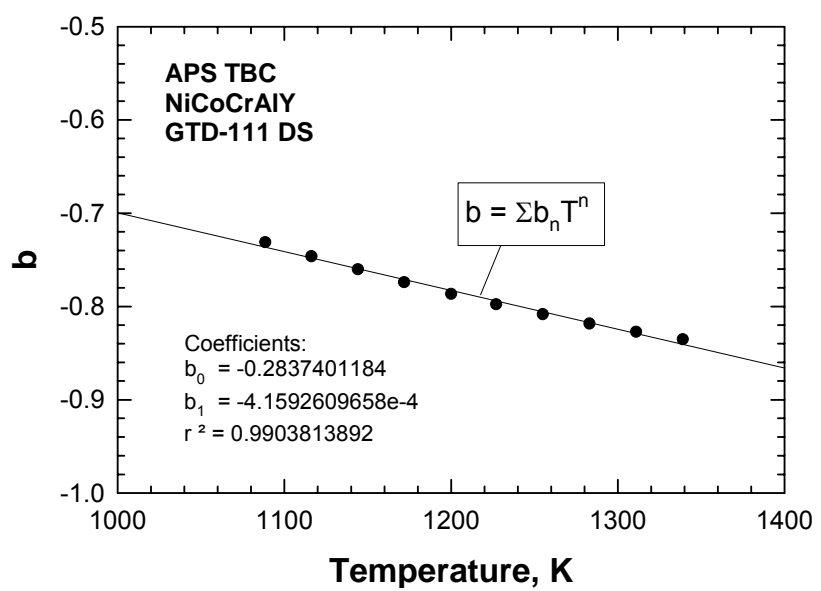

(b)

Figure 5-10. Parameters of the TBC life boundary $\left(N_{s}=10^{a} \tau_{c}^{b}\right)$ as a function of temperature: (a) parameter $a$, and (b) parameter $b$.

\subsection{Task 2A Conclusions-Thermal Barrier Coatings}

- Isothermal and cyclic exposure testing of TBC coated specimens at different temperatures has been in progress. The results showed that the TGO thickness at the TGO/TBC interface increases with increasing exposure time. Variation of bond coating and substrate chemical composition has no affect on the kinetics of TGO growth.

- Thermal cycling tests at two peak temperatures were completed. No significant variation in TBC cracking or spallation was seen among the four coating systems investigated.

- TBC degradation and failure mechanisms included, oxidation sintering, spallation, and TMF cracking. Considering all pertinent failure mechanisms, a TBC lifing model was developed.

- The TBC life model was validated using the experimental data generated in this program. The calculated TBC life values are in good agreement with the test results

\subsection{MCrAlY Coating}

The results of the MCrAIY experimentation and cyclic oxidation testing were presented in the previous semi-annual report are therefore not discussed herein. 


\subsection{TASK 3: NDE OF COATINGS}

\subsection{Task 3.1--NDE System Assemblies and Testing}

Previously, it was shown that the evaluated eddy current system can reliably test and discriminate normal coating conditions from the beta-phase depletion and the cracked coating conditions. The eddy current NDE system relies on its ability to detect and quantify coating conductivity changes. It was unfortunate, but the presence of cracking has caused problems with the coating characterization. Cracking resulted in a major coating conductivity reduction to the extent that it masked the smaller conductivity effect introduced by aged coating that is undergoing beta-phase depletion. This updated report focuses on the original intent of characterizing coating conditions that are not affected by the presence of cracking.

The eddy current evaluated buckets for comparison with destructive analysis results consisted of one $2^{\text {nd }}$ stage bucket from 7FA+ engine and one $2^{\text {nd }}$ stage bucket from 9FA engine. Table 6-1 outlines the operating histories of the $2^{\text {nd }}$ stage buckets that were used in the eddy current testing and evaluation.

Table 6-1. Operating Histories of $2^{\text {nd }}$ Stage Blade Buckets

\begin{tabular}{|l|l|l|l|}
\hline Blade ID & Bucket Type & $\begin{array}{l}\text { Operating } \\
\text { Hrs }\end{array}$ & $\begin{array}{l}\text { No. } \\
\text { Startups }\end{array}$ \\
\hline 970699 & $\begin{array}{l}2^{\text {nd }} \text { Stage }-7 F A+w / G T ~ 33+ \\
\text { Coating }\end{array}$ & 24,000 & 40 \\
\hline 53 & $2^{\text {nd }}$ Stage - 9FA w/GT 29 Coating & 12,000 & (Not known) \\
\hline
\end{tabular}

\section{$7 F A+2^{\text {nd }}$ Stage Bucket - Blade 970699}

This 2 nd stage bucket has undergone 24,000 hours of base-loaded operation with only 40 startups. This blade was taken out of service from the 7FA+ engine (7231FA) and is made of GTD-111 base material with GT 33+ duplex coatings. This blade came out of a baseloaded unit. Figure 6-1 shows an overall layout of the inspected 2nd stage bucket that has been gridded out for eddy current measurements. 

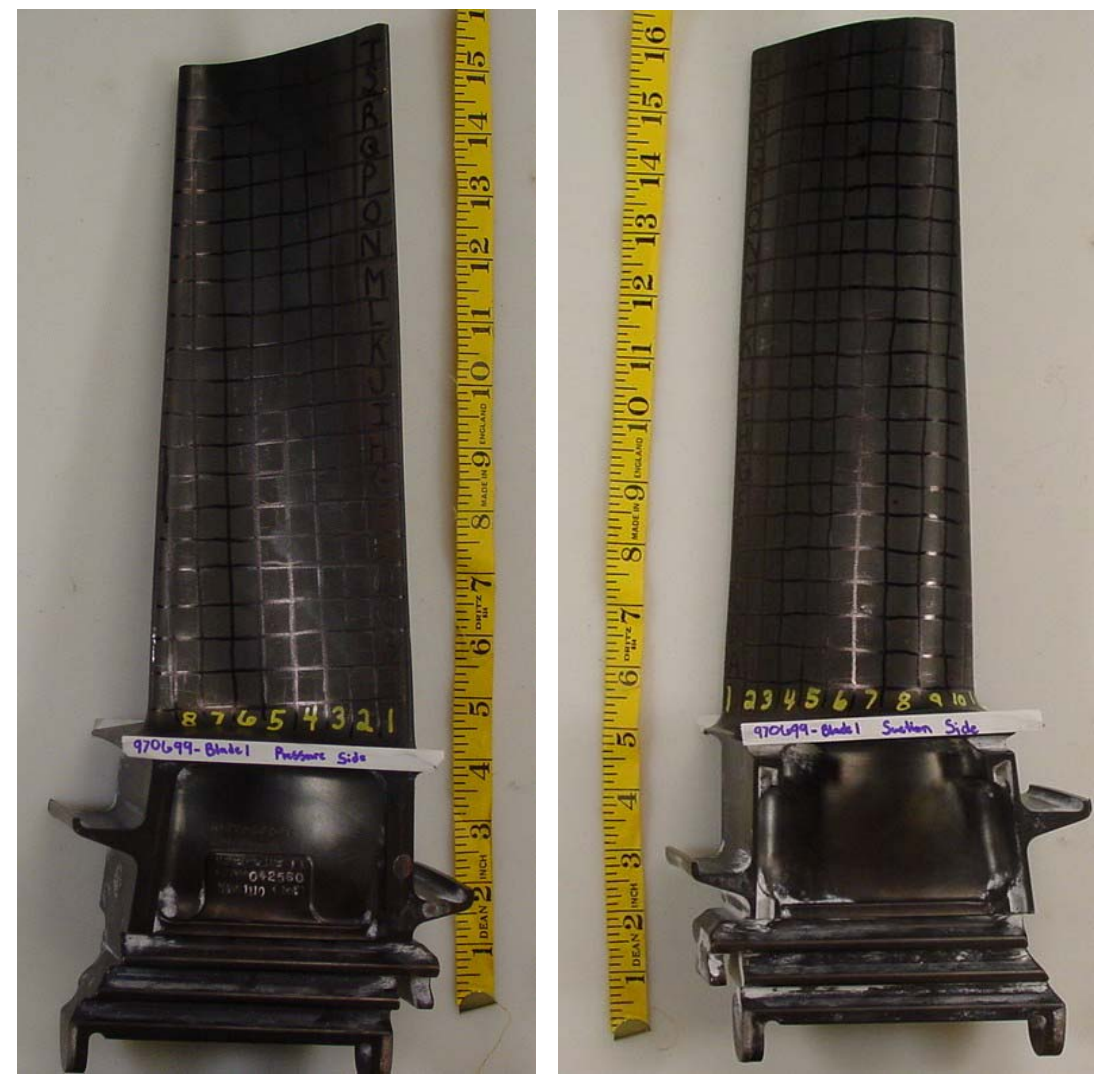

Figure 6-1. Details of the grid marks from the pressure and suction sides of the $2^{\text {nd }}$ stage bucket coated with GT 33+ coating

As shown in the figure, each grid box was approximately $1 / 2$-inch square with alpha- numeric designation. Eddy current measurements were made from the inside of each square grid. The alphabets $A$ through $T$ were assigned in the increasing order of 1 through 20 from the platform to blade tip. Along the chord of the blade, the assigned numbers increased from 111 and 1-8 from the trailing edge to leading edge of the suction and pressure side of the blade, respectively. The number of pressure side scans along the blade height was 20 scans at chord positions \#1 through \#7, while the scan number dropped to 9 at chord position \#8. On the suction side, 20 scans were obtained at chord positions \#1-8, 18 scans at chord position \#9, 10 scans at chord position \#10, and 3 scans at chord position \#11. The areas of interests focused at Sections $E$ and O, which represented approximately $25 \%$ and $75 \%$ of the blade height locations.

\section{FA $2^{\text {nd }}$ Stage Bucket - Blade 53}

Another eddy current testing involved a Frame 9 gas turbine bucket with simplex CoCrAIY coating. Visual inspection showed areas of wear after 12,000 hours of operation. Figure 6- 
2 shows visual appearance of the blade bucket, where wear (highlighted by the darker gray mark) was noted at approximately $50 \%$ of the blade height.

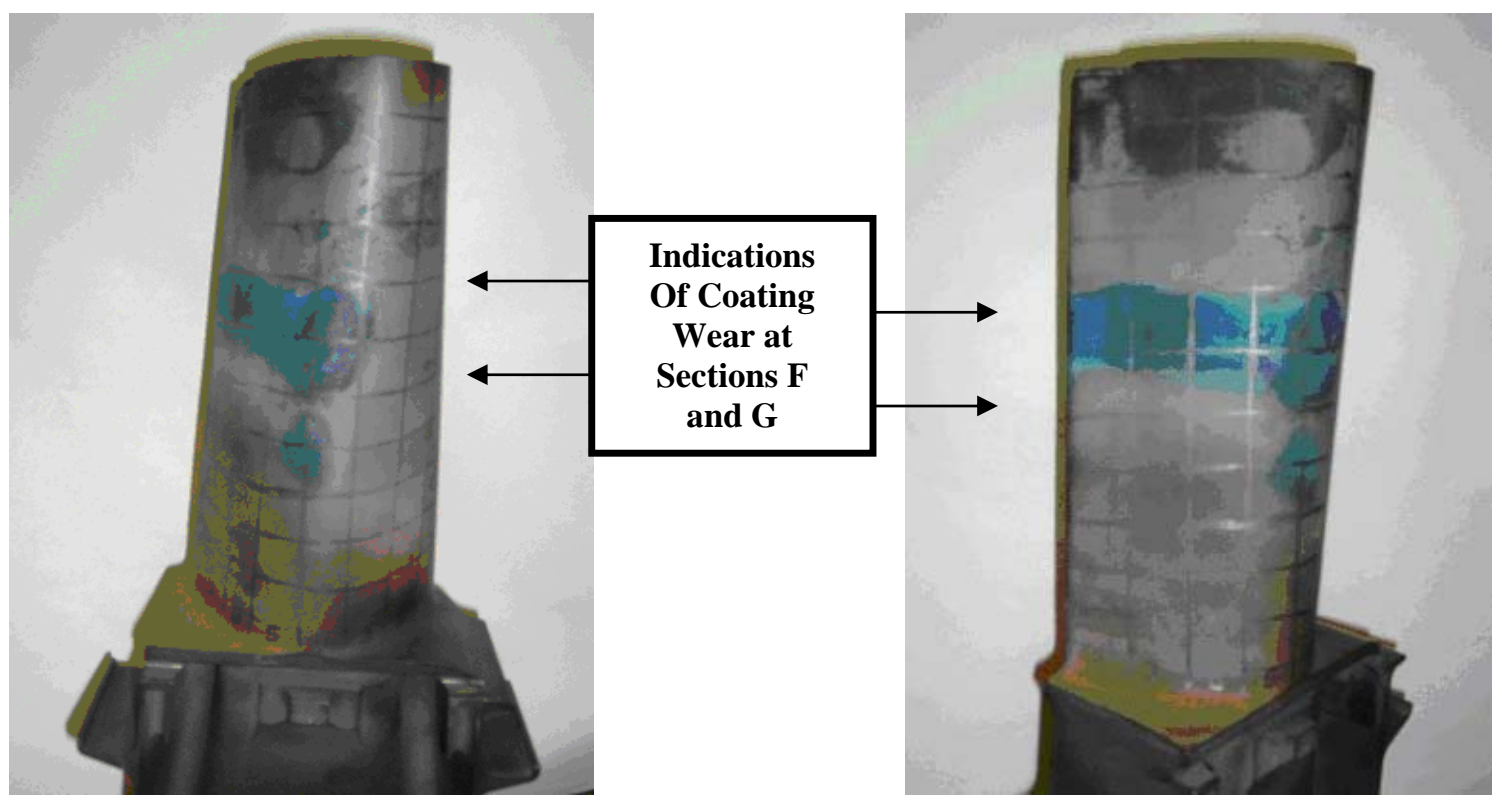

Figure 6-2. Suction Side of Blade 53 showing coating wear highlighted by the darker gray mark 3.3a) Leading Edge of Blade 53 3.3b) Trailing Edge of Blade 53

The blade surface was marked with $3 / 4$-inch square grids. Grids were marked $\mathrm{A}$ through $\mathrm{K}$ along the blade height starting from the platform to the blade tip. Similarly, they were numbered 1 through 8 from the leading edge to trailing edge along the curvature of the blade chord.

\section{Qualitative And Quantitative Eddy Current Analysis Results}

This section provides processed eddy current data from two blade buckets. Both the normalized coil impedance versus frequency and normalized coil impedance versus chord position plots were used to assess, qualitatively, the overall condition of the blade. If it was possible to test and acquire eddy current data from the entire blade surface, the focus shifted to plotting and displaying color-coded contour maps of the calculated normalized coil impedance values. By reviewing such plots, it was possible to identify the areas of interests caused by possible coating degradation and this eventually lead to selection of candidate section(s) for destructive analyses. 
For most aged bucket samples, no associated as-coated calibration samples were available to calibrate and optimize the eddy current analysis system. Consequently, destructive analysis results were used in some instances to optimize the eddy current inversion algorithms to evaluate relevant parameters of interests.

\section{Blade970699 - 7FA+ 2nd Stage Bucket with GT 33+ Coating}

This section showed comparative evaluation of destructive sectioning done at Sections $\mathrm{E}$ ( $25 \%$ height) and $\mathrm{O}(75 \%$ height) with eddy current estimates.

Figure 6-3 shows normalized impedance plots from Sections $E$ and $O$ along with the composite contour plot of normalized impedance plot from the entire suction side. No obvious cracking (negative slope) or typical beta-depletion (flat line with no slope) curves were noted. In general, higher normalized coil impedance values were noted at Section $\mathrm{E}$ than Section $O$. This generally indicated that more normal coating conditions are found at Section E than Section O.
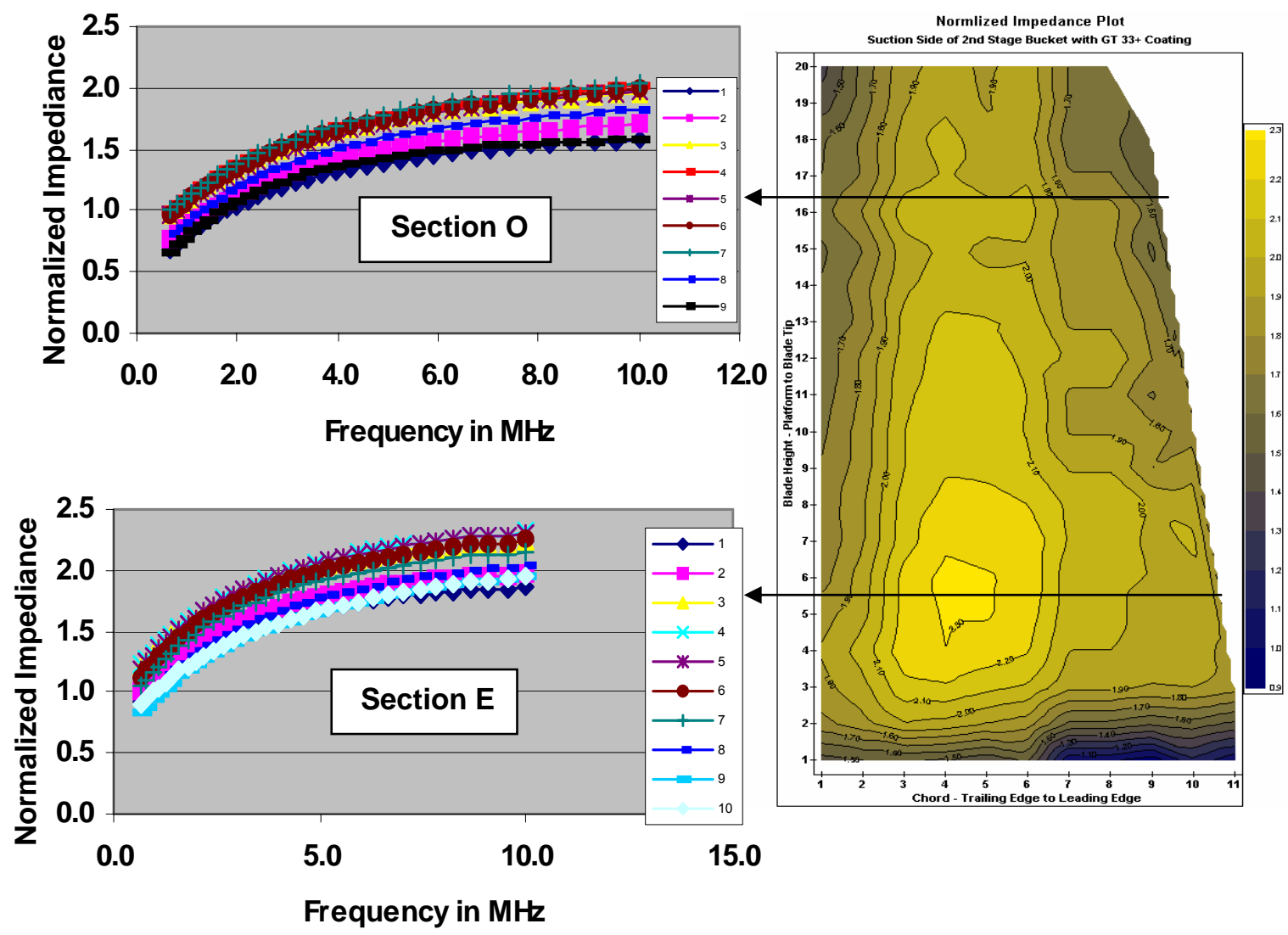

Figure 6-3. Normalized Coil Impedance Plots from Sections E and $O$ and a Composite Contour Plot of Normalized Impedance Plot from the Entire Suction Side 
Figure 6-4 shows representative views of the coating conditions from Sections $E$ and $O$ using an electron microscope at respective magnifications. There was no evidence of topcoats or over-aluminized coatings present beside the bond coat.

The indicated topcoat represented either the $\beta$-phase depletion of topcoat or beta-phase depletion of top bond coat. In either case, the destructive test results showed no presence of over-aluminized topcoats.
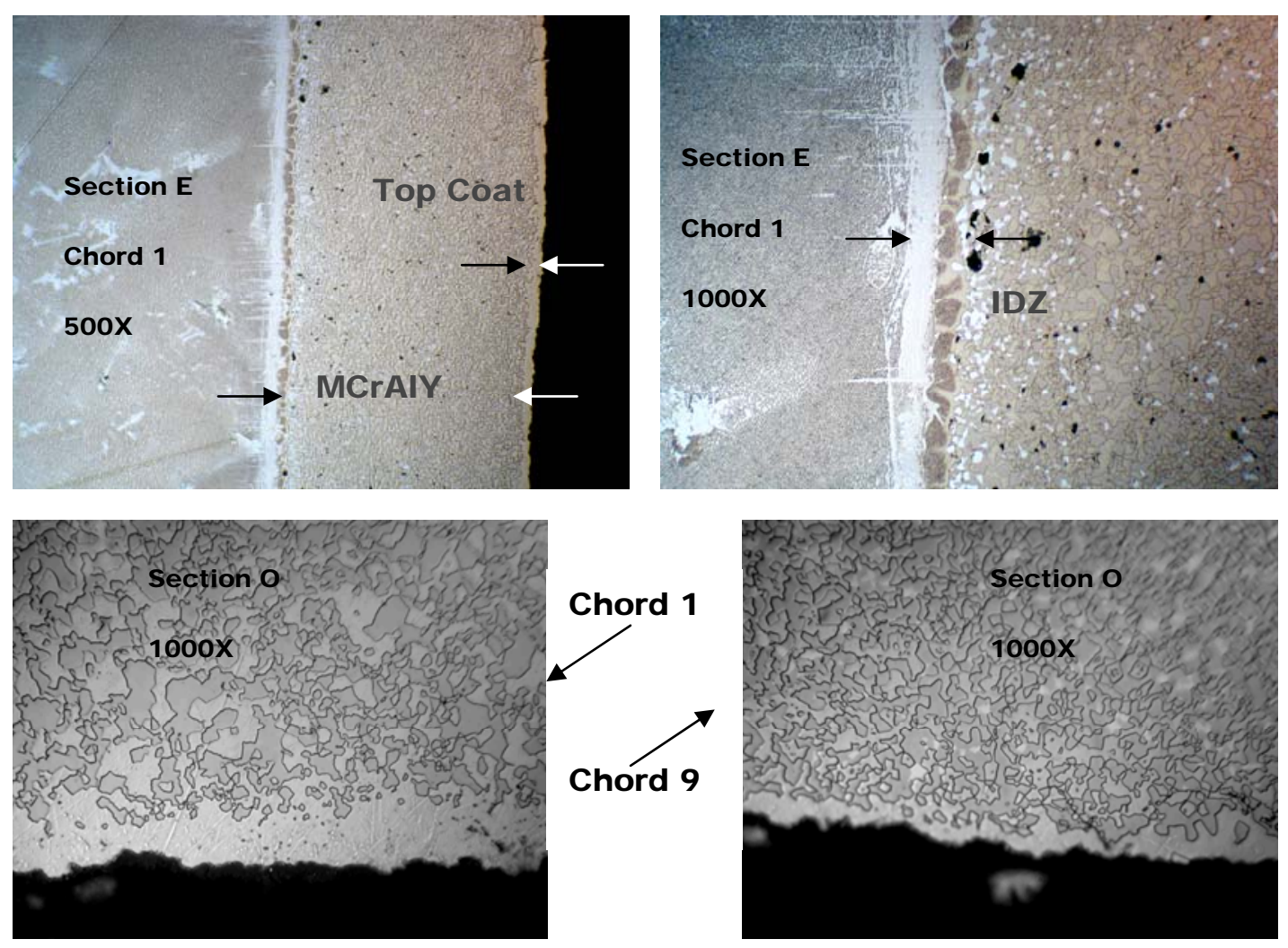

Figure 6-4. Coating Profiles from Sections E and O at Respective Chord Locations Showing Presence of no Over-aluminized Topcoats

Table 6-2 shows the averaged measurements of topcoat, the combined topcoat and bond coat, and inter-diffusion zone thickness values. 
Table 6-2. Averaged Coating Thickness Measurements - Based on Two Measurements per Chord Location

\begin{tabular}{|l|l|l|l|}
\hline $\begin{array}{l}\text { Grid } \\
\text { location }\end{array}$ & $\begin{array}{l}\text { Topcoat } \\
(U m)\end{array}$ & $\begin{array}{l}\text { Topcoat+Bond } \\
\text { Coat (um) }\end{array}$ & $\begin{array}{l}\text { Inter-Diffusion } \\
\text { Zone (um) }\end{array}$ \\
\hline E1/O1 & $11 / 12$ & $236 / 224$ & $17 / 38$ \\
\hline E2/O2 & $5 / 13$ & $232 / 213$ & $23 / 31$ \\
\hline E3/O3 & $1 / 6$ & $221 / 199$ & $19 / 27$ \\
\hline E4/O4 & $0 / 4$ & $200 / 193$ & $15 / 16$ \\
\hline E5/O5 & $0 / 3$ & $205 / 185$ & $16 / 22$ \\
\hline E6/O6 & $0 / 0$ & $203 / 208$ & $16 / 23$ \\
\hline E7/O7 & $0 / 0$ & $203 / 213$ & $15 / 20$ \\
\hline E8/O8 & $0 / 3$ & $190 / 223$ & $15 / 20$ \\
\hline E9 & $0 / 4$ & $185 / 224$ & $10 / 24$ \\
\hline E10 & 0 & 175 & 13 \\
\hline Average & $1.7 / 5.0$ & $205.0 / 209.1$ & $15.9 / 24.6$ \\
\hline
\end{tabular}

Although small amount of topcoats were measured, it is believed that these readings represent beta-depleted zones and not over-aluminized topcoats. Basically, there were no indications of topcoats remaining on the suction side of this $2^{\text {nd }}$ stage bucket. Based on the tabulated measurements, a slightly higher bond coat thickness value was noted at Section $\mathrm{O}$ than at Section $\mathrm{E}$. Also, greater inter-diffusion thickness value was noted from Section $\mathrm{O}$ than Section E. This indicated that Section $\mathrm{O}$ was exposed, as expected, to higher firing temperatures than Section $\mathrm{E}$.

Table 6-3 shows comparative analysis of topcoat thickness estimates. This table showed that no reliable estimates of actual topcoat thickness values by eddy current were possible when no topcoats were present. The analysis errors stemmed from the eddy current analysis software, which relied on an initial condition of assuming the presence of both the topcoat and bond coat.

Table 6-3. Comparison of Topcoat Estimates

\begin{tabular}{|l|l|l|}
\hline $\begin{array}{l}\text { Grid } \\
\text { location }\end{array}$ & $\begin{array}{l}\text { Topcoat (um) } \\
\text { Met Results }\end{array}$ & $\begin{array}{l}\text { Topcoat } \\
\text { (um) } \\
\text { NDE Results }\end{array}$ \\
\hline E1/O1 & $11 / 12$ & $23 / 8$ \\
\hline E2/O2 & $5 / 13$ & $0 / 5$ \\
\hline E3/O3 & $1 / 6$ & $9 / 18$ \\
\hline E4/O4 & $0 / 4$ & $97 / 55$ \\
\hline E5/O5 & $0 / 3$ & $93 / 53$ \\
\hline E6/O6 & $0 / 0$ & $68 / 45$ \\
\hline E7/O7 & $0 / 0$ & $77 / 33$ \\
\hline E8/O8 & $0 / 3$ & $6 / 86$ \\
\hline E9 & $0 / 4$ & $91 / 36$ \\
\hline E10 & 0 & 101 \\
\hline
\end{tabular}




\section{\begin{tabular}{|l|l|l|}
\hline Average & $1.7 / 5.0$ & $56.5 / 37.7$ \\
\hline
\end{tabular}}

Figure 6-5 shows details of the coating composition from chord O2. The topcoat is devoid of $\beta$ phase and is replaced by gamma phase. Since the average weight percent of aluminum in the topcoat is around $3 \%$ from the maximum of $26 \%$, the topcoat was all but gone. The overall eddy current measurements were reflective of the combined topcoat and bond coat conditions. Without the as-coated sample, it was only possible to monitor changes in the combined effect of both coatings. Because of this condition, the eddy current estimates represented the combined thickness values of the topcoat and bond coat.
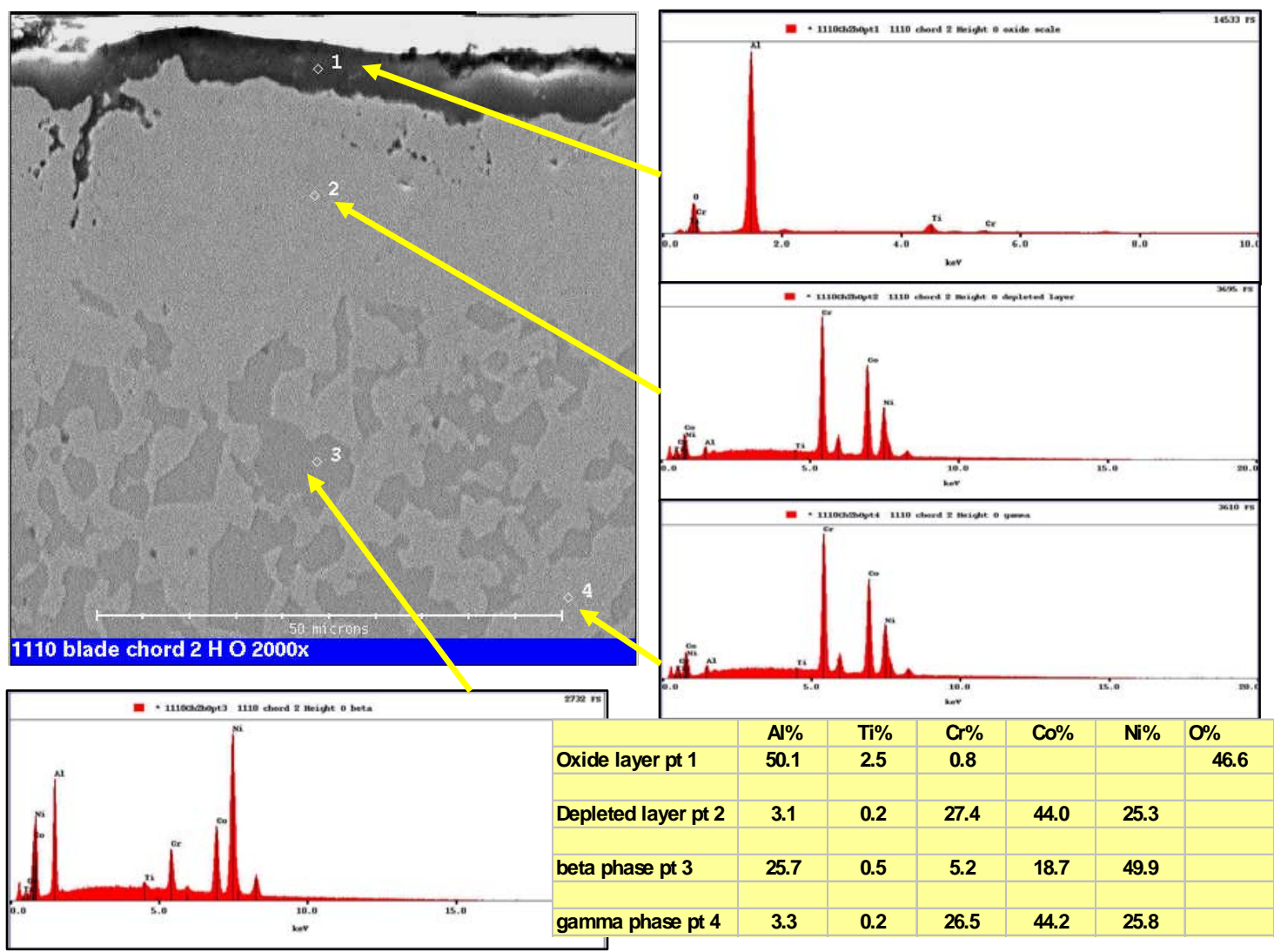

Figure 6-5. Detail Coating Composition of Beta- and Gamma-Phase Found in Chord 02

Table 6-4 shows comparison of the combined coating thickness value estimates between destructive and eddy current estimates. For eddy current estimates, both 3-layer and 4layer inversion algorithms were tested. Since there were no topcoats, the 3-layer inversion algorithm provided more accurate combined coating thickness value estimates in comparison to a 4-layer inversion algorithm.

For Sections $\mathrm{E}$ and $\mathrm{O}$, the respective thickness estimate errors of $+4.4 \%$ and $+3.8 \%$ were obtained using the 3-layer inversion program. In contrast, the respective thickness estimate errors of $+6.4 \%$ and $-5.8 \%$ were obtained using the 4 -layer inversion algorithm. 
Table 6-4. Comparison of Combined Coating Thickness Estimates Based on Destructive Results to 3- and 4-layer Eddy Current Inversion Program Results

\begin{tabular}{|l|l|l|l|l|l|}
\hline $\begin{array}{l}\text { Grid } \\
\text { location }\end{array}$ & $\begin{array}{l}\text { Topcoat+Bond } \\
\text { Coat (um)-Met }\end{array}$ & $\begin{array}{l}3 \text { Layer } \\
\text { Coat (um) }\end{array}$ & $\begin{array}{l}\text { Error } \\
(\%)\end{array}$ & $\begin{array}{l}4 \text { layer } \\
\text { Coat (um) }\end{array}$ & $\begin{array}{l}\text { Error } \\
(\%)\end{array}$ \\
\hline E1/O1 & $236 / 224$ & $227 / 222$ & $-4 /-1$ & $214 / 214$ & $-9 /-4$ \\
\hline E2/O2 & $232 / 213$ & $214 / 222$ & $-8 /+4$ & $219 / 209$ & $-6 /-2$ \\
\hline E3/O3 & $221 / 199$ & $216 / 206$ & $-2 /+4$ & $202 / 182$ & $-9 /-9$ \\
\hline E4/O4 & $200 / 193$ & $204 / 246$ & $-2 /+27$ & $246 / 219$ & $+23 /+13$ \\
\hline E5/O5 & $205 / 185$ & $195 / 212$ & $-5 /+10$ & $240 / 169$ & $+17 /-12$ \\
\hline E6/O6 & $203 / 208$ & $251 / 233$ & $+24 /+26$ & $249 / 182$ & $+23 /+2$ \\
\hline E7/O7 & $203 / 213$ & $232 / 190$ & $+14 /-11$ & $215 / 168$ & $-6 /-21$ \\
\hline E8/O8 & $190 / 223$ & $196 / 196$ & $+3 /-12$ & $194 / 208$ & $+2 /-7$ \\
\hline E9 & $185 / 224$ & $221 / 195$ & $+19 /-13$ & $225 / 197$ & $+22 /-12$ \\
\hline E10 & 175 & 183 & +5 & 187 & +7 \\
\hline Average & $205.0 / 209.1$ & $213.9 / 213.6$ & $+4.4 /+3.8$ & $219.1 / 194.2$ & $+6.4 /-5.8$ \\
\hline
\end{tabular}

Table 6-5 compares measured Al wt\% remaining from the bond coat regions to bond coat conductivity values obtained based on the 3-layer inversion program. If the 4-layer inversion results were used, inaccurate conclusion can be drawn. Basically, the met results showed that on the average, more Al wt\% was found in Section E than section O $(8.4 \%$ vs $7.5 \%)$. The eddy current estimates showed that higher conductivity values were correctly estimated for Section E than for Section O $(0.929 \mathrm{MS} / \mathrm{m}$ vs $0.883 \mathrm{MS} / \mathrm{m})$. 
Table 6-5. Comparison of Wt\% Al Remaining to Eddy Current Conductivity Estimates

\begin{tabular}{|l|l|l|l|l|}
\hline $\begin{array}{l}\text { Grid } \\
\text { Number }\end{array}$ & $\begin{array}{l}\text { Grid E } \\
\text { Met (wt\%) }\end{array}$ & $\begin{array}{l}\text { Grid E/F } \\
\text { Cond } \\
(\mathrm{MS} / \mathrm{m})\end{array}$ & $\begin{array}{l}\text { Grid O } \\
\text { Met (wt\%) }\end{array}$ & $\begin{array}{l}\text { Grid O/P } \\
\text { Cond (MS/m) }\end{array}$ \\
\hline 1 & 7.9 & 0.892 & 7.7 & 0.895 \\
\hline 2 & 9.1 & 0.929 & 8.1 & 0.933 \\
\hline 3 & 8.0 & 0.989 & 7.8 & 0.927 \\
\hline 4 & 8.2 & 0.983 & 8.1 & 0.959 \\
\hline 5 & 8.3 & 1.000 & 8.4 & 0.925 \\
\hline 6 & 8.7 & 0.980 & 9.4 & 0.927 \\
\hline 7 & 8.0 & 0.978 & 8.8 & 0.863 \\
\hline 8 & 8.6 & 0.636 & 8.7 & 0.929 \\
\hline 9 & 8.6 & 0.931 & 8.2 & 0.585 \\
\hline 10 & 8.3 & 0.939 & & \\
\hline Average & 8.4 & 0.929 & 7.5 & 0.883 \\
\hline
\end{tabular}

\section{Blade 53 - 9FA $2^{\text {nd }}$ Stage Bucket with GT 29 Coating}

As shown in Figure 6-2, there were obvious areas of coating wear that were noticeable after 12,000 hours of operation. The F-SECT system's flexibility and capability to inspect unknown coating conditions were demonstrated even on the bucket that was found to be magnetic. Having no access to as-coated blade bucket or information about coating conditions, no quantitative coating evaluation was possible.

This section provides destructive analysis results, including Energy Dispersive Spectroscopy (EDS) results. The obtained information was used to analyze and understand the eddy current signal responses that were generated from the cutout sections. Figure 6-6 shows the cuts that were made in the middle of Sections $F$ and $G$. The worst conditions were observed at F4 and G4 (where grid numbers increased from 1 to 8 from the leading edge to trailing edge). 


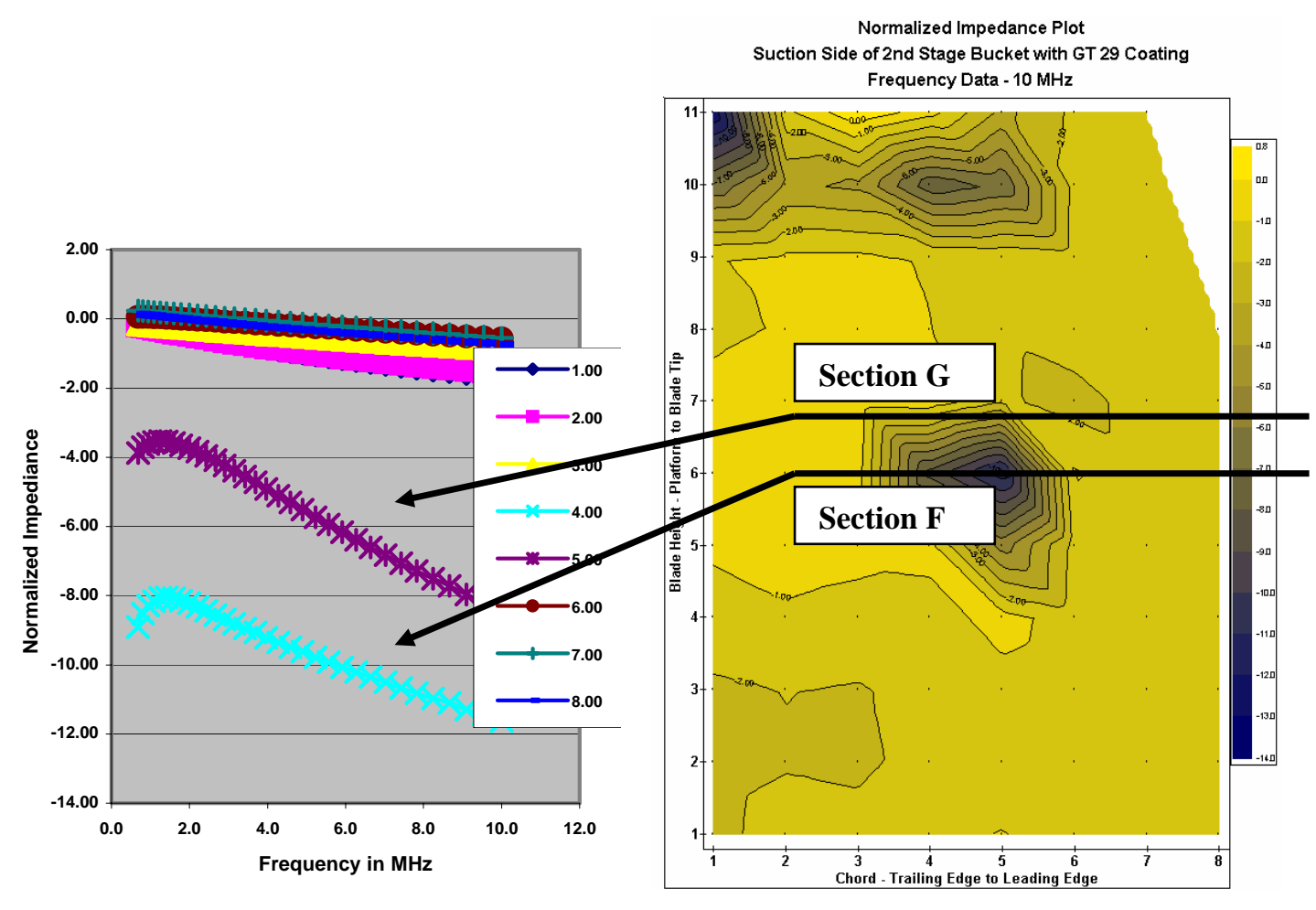

Figure 6-6. Suction side of Blade 53 showing cut lines across Sections F and G and associated decrease in normalized coil impedance values

Figure 6-7 shows SEM photomicrographs obtained from Sections F4, F5, and F6.

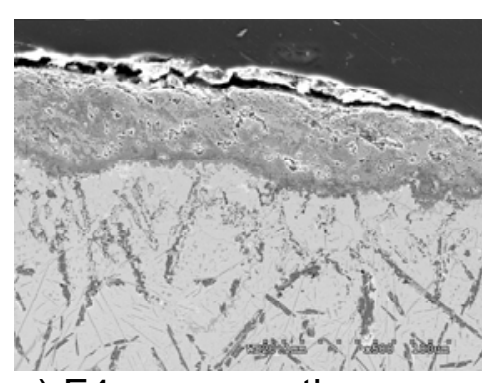

a) F4 cross-section

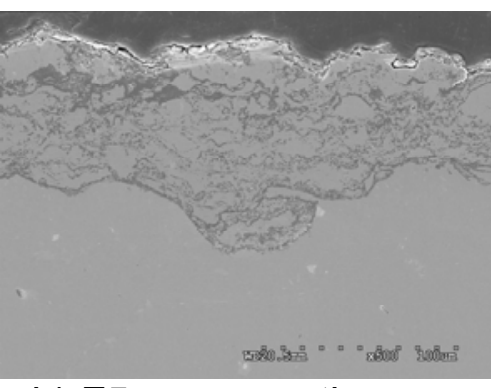

b) F5 cross-section

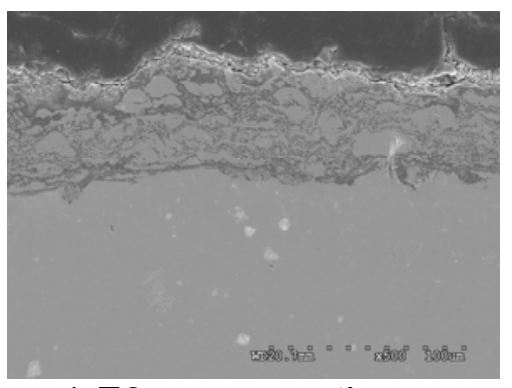

c) F6 cross-section

Figure 6-7. SEM photomicrographs of F4, F5, and F6 Transverse Sections

Figure 6-7a) clearly shows oxidation of CoCrAlY coating accompanied by diffusion of aluminum into the base metal. This diffusion process into the base metal is shown as 
columnar AIN and finely dispersed TiN precipitates. As will be shown later from the chemistry of coatings by wt $\%$, aluminum is decreased to $10 \%$ along with chromium, which is also down to $8.4 \%$. The oxygen concentration, however, was high at $24.5 \%$. The coating on this F4 section was heavily oxidized and offered no protection to the base metal. These precipitates lead to weakening of the base metal alloy due to high residual stresses. In comparison, no base metal precipitates were visible from Sections F5 and F6. Within coating, no obvious oxidation of the coating was noted except for the oxide deposits on top of the coating. Also, it was possible to see darker $\beta$-phase (CoAl) particles dispersed unevenly within gray-colored $\gamma$-phase solution. The average coating thickness was 45,60 , and 55 microns for F4, F5, and F6, respectively. Visually, no obvious differences were noted at F5 and F6 but the eddy current responses at positions 5 and 6 clearly showed two different signal responses. Once again, it was necessary to look at the chemistry of coating based on the EDS results in wt\% Al remaining. After averaging the spectrum readings, it was determined that aluminum content was around $10 \%$ at $\mathrm{F} 4,12.5 \%$ at $\mathrm{F} 5$, and $19.9 \%$ at F6. These differences in the aluminum content were detected reliably by using the sensitive F-SECT system.

The next question involved the explanation for the characteristic "hook" pattern observed at a lower frequency (see Figure 6-6). As mentioned earlier, this coated bucket exhibited magnetic characteristics based on the attraction of a small magnet placed alongside each of the outlined grid squares. The areas such as F4 and G4 exhibited stronger attractions than other outlined grid areas. Since the nickel-based GTD-111 substrate alloy is not magnetic, this magnetic behavior is more likely to cause depletion of chromium, which results in chromium oxide deposits. The chemical composition by weight percent for chromium in CoCrAly coating, based on a literature survey, showed a range of $25-33 \%$. According to the EDS results, the chromium content averaged from a low of $8.4 \%$ at $\mathrm{F} 4,15.6 \%$ at $\mathrm{F} 6$, and $18.6 \%$ at F5. The resultant oxide can be found both on the top scale, which can spall off, and in the diffusion interface. The F5 cross-section showed the presence of a deposit approximately 35 microns thick, while no appreciable deposit was noted at F6. The spectrum analysis by weight percent of deposit at F5 showed $40 \%$ carbon, $21 \%$ cobalt, $13 \%$ chromium, $10 \%$ aluminum, $9 \%$ nickel, and $7 \%$ oxygen. Based on the spectrum analysis of the diffusion interface, the chromium content was found to be $10 \%$ at $\mathrm{F} 4,22 \%$ at $\mathrm{F} 5$, and $16.2 \%$ at F6. So, it's possible that the combined presence of chromium oxide both on the top surface and in the diffusion interface may have resulted in the "hook" pattern noted at F5 but not at F6.

Figure 6-8 shows SEM photomicrographs obtained from Sections G4, G7, and G8. Unfortunately, no SEM photomicrographs were available from G1, G2, and G3 locations. 


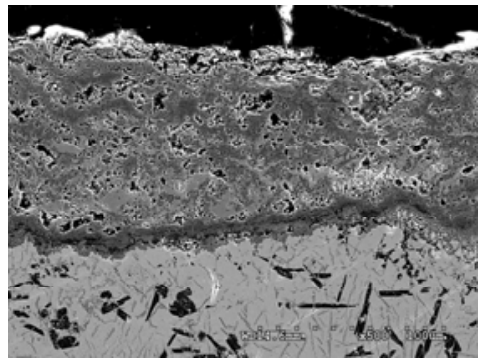

a) G4 Cross-section

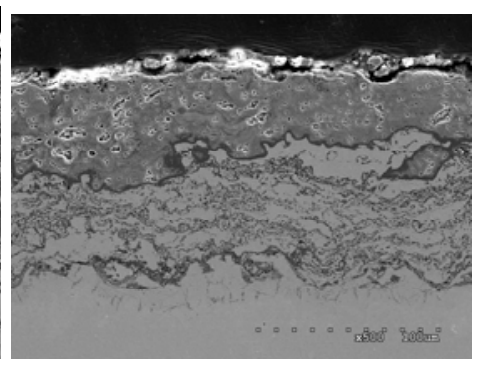

b) G7 cross-section

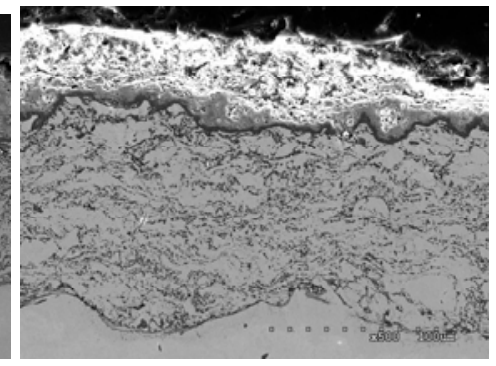

c) G8 cross-section

Figure 6-8. SEM Photomicrographs of G4, G7, and G8 Transverse Sections

As in F4, the G4 coating is heavily oxidized, resulting in the AIN and TiN precipitates to form in the base metal. There is no effective coating left at this location. Noticeable deposit layers were observed at G7 and G8, where average deposit thickness was around 55 and 40 microns, respectively. However, the respective coating thickness of around 60 and 100 microns remained with associated aluminum weight percent of $10.5 \%$ and $11.8 \%$. Based strictly on the aluminum weight percent, the G8 cross-section should have a slightly higher conductivity value associated with the higher coil impedance values. The eddy current signal response showed just the opposite effect where $\mathrm{G} 7$ coil impedance values were higher than G8 coil impedance values. There were no visible oxidation at the diffusion interface at $\mathrm{G} 7$ and $\mathrm{G} 8$. The spectrum analysis of the interface showed, on the average, $16.4 \%$ aluminum concentration at $\mathrm{G} 7$ and $11.4 \%$ aluminum concentration at G8. Perhaps, this higher combined aluminum concentration at $\mathrm{G} 7$ resulted in the eddy current signal responses to be higher at $\mathrm{G} 7$ than $\mathrm{G} 8$.

Table 6-6 summarizes the chemical composition in weigh percent of the following layers: CoCrAlY coating, the diffusion interface, and the base metal. 
Table 6-6. Chemical Composition in Weight Percent from EDS

$\begin{array}{llllll}\text { Location F4 } & \text { F5 } & \text { F6 } & \text { G4 } & \text { G7 } & \text { G8 } \\ \text { Coating AVG Thickness(um)45 } & 60 & 55 & 100 & 60 & 100 \\ \text { Deposit AVG Thickness(um) } & 35 & & & 55 & 40\end{array}$

Coating Chemistry

$\begin{array}{lllllll}\mathrm{O} & 24.5 \% & 4.2 \% & 9.5 \% & 26.5 \% & 4.8 \% & 7.2 \% \\ \mathrm{Al} & 10.0 \% & 12.5 \% & 19.9 \% & 11.8 \% & 10.5 \% & 11.8 \% \\ \mathrm{Ti} & 0.0 \% & 0.0 \% & 0.0 \% & 0.2 \% & 0.0 \% & 0.3 \% \\ \mathrm{Cr} & 8.4 \% & 18.6 \% & 15.6 \% & 10.6 \% & 19.9 \% & 19.4 \% \\ \mathrm{Co} & 17.7 \% & 37.3 \% & 38.5 \% & 28.7 \% & 39.7 \% & 40.6 \% \\ \mathrm{Ni} & 22.3 \% & 16.8 \% & 9.9 \% & 14.8 \% & 17.3 \% & 16.6 \% \\ \mathrm{C} & \text { Balance } & & & & & \end{array}$

Interface Chemistry

$\begin{array}{lllllll}\mathrm{O} & 27.4 \% & 5.6 \% & 7.9 \% & 27.9 \% & 6.7 \% & 8.0 \% \\ \mathrm{Al} & 10.3 \% & 19.5 \% & 14.2 \% & 12.3 \% & 16.4 \% & 11.4 \% \\ \mathrm{Ti} & 1.8 \% & 0.0 \% & 0.0 \% & 3.2 \% & 4.8 \% & 6.3 \% \\ \mathrm{Cr} & 10.0 \% & 22.0 \% & 16.2 \% & 23.2 \% & 17.3 \% & 17.6 \% \\ \mathrm{Co} & 10.7 \% & 37.3 \% & 41.4 \% & 14.5 \% & 30.6 \% & 34.4 \% \\ \mathrm{Ni} & 18.8 \% & 15.7 \% & 10.3 \% & 14.2 \% & 17.0 \% & 17.6 \% \\ \mathrm{C} & \text { Balance } & & & & & \\ & & & & & & \\ \text { Base Metal Chemistry } & & & & & & \\ \mathrm{O} & 0.0 \% & 0.0 \% & 0.0 \% & 0.0 \% & 0.0 \% & 0.0 \% \\ \mathrm{Al} & 8.6 \% & 3.2 \% & 3.7 \% & 4.7 \% & 3.0 \% & 2.9 \% \\ \mathrm{Ti} & 6.2 \% & 4.7 \% & 5.6 \% & 7.0 \% & 4.5 \% & 5.0 \% \\ \mathrm{Cr} & 11.3 \% & 14.8 \% & 13.2 \% & 12.4 \% & 13.3 \% & 13.6 \% \\ \mathrm{Co} & 9.9 \% & 9.2 \% & 10.1 \% & 9.1 \% & 7.7 \% & 10.4 \% \\ \mathrm{Ni} & 60.0 \% & 57.9 \% & 57.9 \% & 60.1 \% & 60.7 \% & 58.6 \% \\ \mathrm{C} & \text { Balance } & & & & & \end{array}$

This work has demonstrated that due to oxidation and $\beta$-phase depletion, the coating conductivity has dropped below the base metal conductivity value. Also, due to chromium depletion, some areas were found to be magnetic as characterized by the "hook" pattern of the eddy current signal responses at lower operating frequencies.

What is not clear at this point is the expected shape of the coil responses from the nominal coating. This nominal coating condition is more likely found closer to the blade platform where temperature exposure is lower. However, the eddy current responses from Sections $A$ and $B$ all showed negative slopes with nominal impedance values ranging from -0.2 to 2.5. So, it is possible that the conductivity of this particular coating is less than the base metal. 


\subsection{Conclusions-Task 3}

A state-of-the-art F-SECT system has been assembled to test and evaluate both duplex and simplex metallic coatings of the 7FA and the 9FA blade buckets. The assembled F-SECT system demonstrated its capability to provide both qualitative and quantitative information about coating conditions.

Capability of the F-SECT system to detect, discriminate, and characterize such coating conditions as normal coating, $\beta$-phase depletion, and cracked coating was already demonstrated and reported in previous reports. In addition, it was possible based on the built-in inversion program to estimate coating layer thickness vales and the associated conductivity values of NiCoCrAlY bond coat and GTD-111 substrate from service-aged 7FA second stage bucket with GT 33+ coatings. When topcoats are completely depleted, however, no reliable estimates of the topcoat thickness values were obtained. Thus, it was necessary to evaluate the combined topcoat and bond coat thickness value instead of the individual coating layers. By focusing on the total coating thickness, more accurate overall coating thickness values were obtained.

Additional testing showed that F-SECT is capable of assessing a service-aged bucket coated with CoCrAlY simple coating (GT 29). Due to heavy oxidation of CoCrAlY coating accompanied by diffusion of aluminum into the substrate as columnar AIN and finely dispersed TiN precipitates, no effective base metal protection was provided, especially, at $50 \%$ of the blade height location. In addition to the loss of coating protection, chromium depletion caused the GT29 coating to become magnetic. The magnetic characteristic of the coating was identified from the unique hook-pattern impedance plot obtained at low frequency. By reviewing the normalized coil impedance plots over frequency, it was possible to detect and discriminate $\beta$-phase depletion of coating from the base metal corrosion. Due to lack of normal coatings found on the evaluated bucket, no quantitative analysis was possible.

Individual cutout sections can be evaluated using plots of normalized impedance versus frequency or normalized impedance versus chord position. In general, normal coating/substrate conditions present highest normalized impedance curves with positive slopes, followed next by almost flat curves representing $\beta$-phase depletion, and finally curves with negatives slopes representing the presence of crazed cracking and possible corrosion of base metal. To review the entire airfoil condition, a colored contour map of normalized impedance values was plotted to show the affected area of interest. In general, more degradation on the suction side was noted at the leading edge of the blade surface. This year, much progress has been made in the data display presentation by plotting colored contour maps of those calculated parameters, such as normalized impedance values, conductivity values, and coating thickness values. By reviewing the colored contour map of the entire bucket, it was easier to locate the problem areas associated with coating degradation. The colored contour maps showed general agreement of higher normalized 
impedance values to higher conductivity values. Also, higher $\sigma$ values correlated better with wt.\% of remaining aluminum than the area fraction of $\beta$-phase particles remaining.

The progress made to date combined with other on-going efforts will hopefully result in generating a calibration curve that would correlate $\sigma$ of coatings to wt. $\%$ of aluminum remaining in the topcoat or combined topcoat/bond coat layer. The estimated wt.\% of aluminum remaining can then be used as input to COATLIFE to assess the remaining useful coat life. 


\subsection{TASK 4: FIELD VALIDATION OF COATLIFE AND NDE}

The objective of this task is to validate the predictive capabilities of COATLIFE and the eddy current NDE methodology on field-operated coated turbine buckets.

Following NDE evaluation, two service-run GE Frame 7FA blades (\# 7 and 57) were received at SwRI. It was reported that Blade 7 had seen 8286 hours of operation with 670 start-stop cycles. Blade 57 had seen 2000 hours of operation with 219 start-stop cycles after the blade was refurbished. The blade was refurbished after it had seen 14,795 hours and had experienced 518 start-stop cycles.

The airfoil section of the blades divided into squares or grids as illustrated in Figure 7-1. NDE measurements were taken form all the squares marked on the blades. For NDE validation, three transverse sections at the $25 \%, 50 \%$, and $75 \%$ blade height locations were removed from each blade. These locations corresponds to transverse locations marked as "A", " $C$ " and "D" on Blade 7 and "B", "E", and "G" on Blade 57. Metallurgical mounts were prepared from all these sections using standard metallographic techniques. The locations of the mounts are illustrated in Figure 7-2.
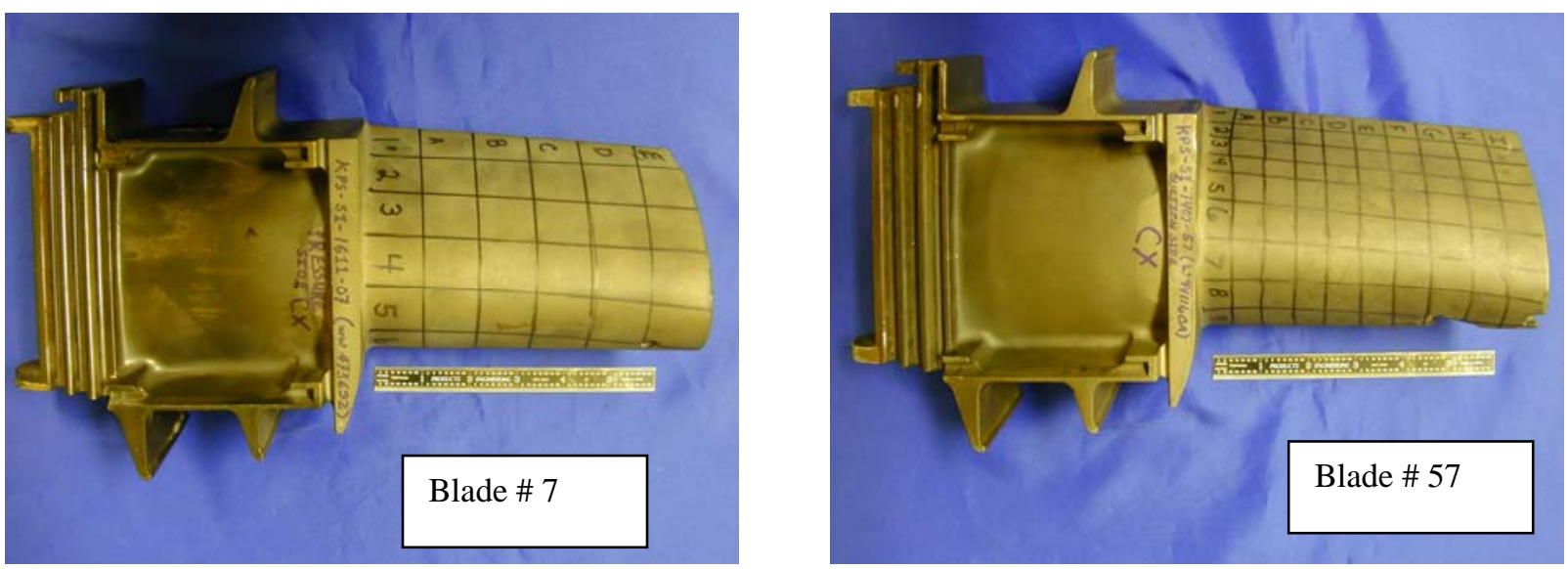

Figure 7-1: Photograph of Blade 7 showing grids on the airfoil sections of Blades 7 and 57 where NDE measurements were taken. Note smaller squares on Blade 57. 

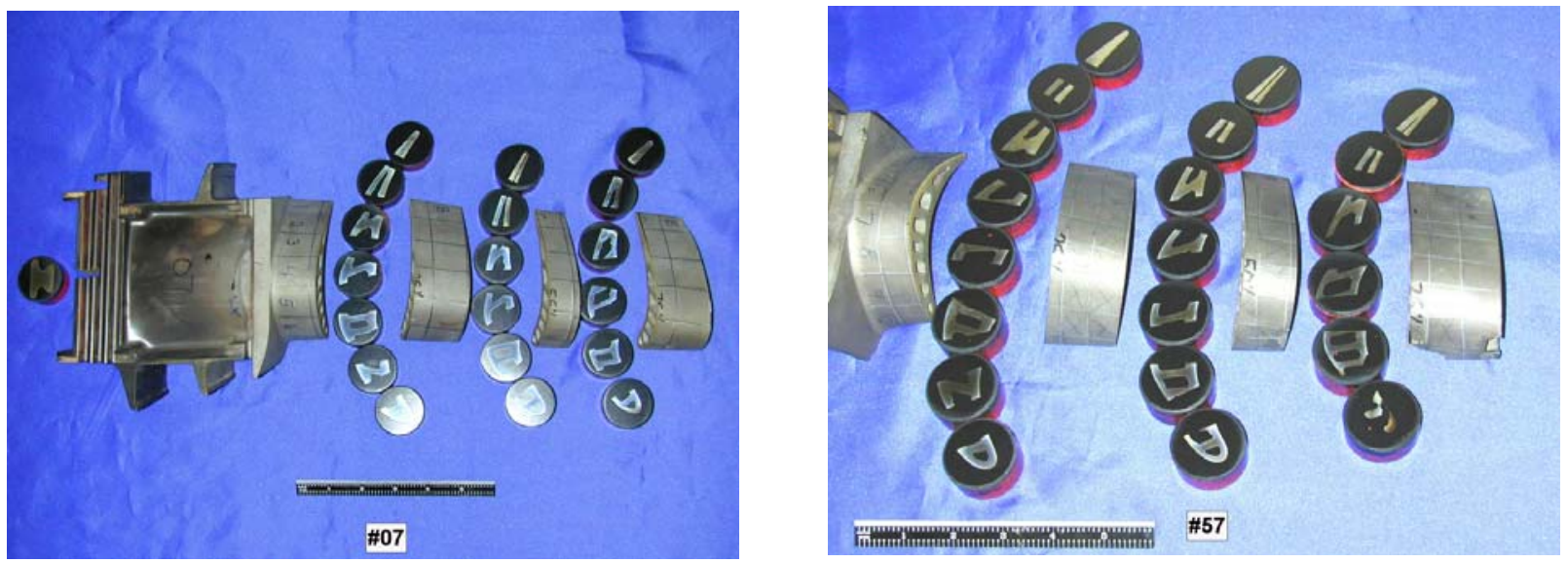

Figure 7-2: Photographs showing metallurgical sample locations in Blade 7 and 57

These examinations of the mounts showed that these blades had over aluminized NiCoCrAlY coating (GT 33 Plus). Thermal-mechanical fatigue (TMF) cracks were seen on the convex side of the airfoil near the leading edge of Blade 7. Majority of the cracks in this blade were shallow and only a crack in the blade at $25 \%$ height had extended into the substrate. Blade 57 was more severely cracked than Blade 7 . On Blade 57 , TMF cracks were observed on both the convex (suction) and concave (pressure) sides of Blade 57. Several cracks in Blade 57 at different blade heights were extended into the substrate. Morphology of TMF cracks is shown in Figure 7-3.
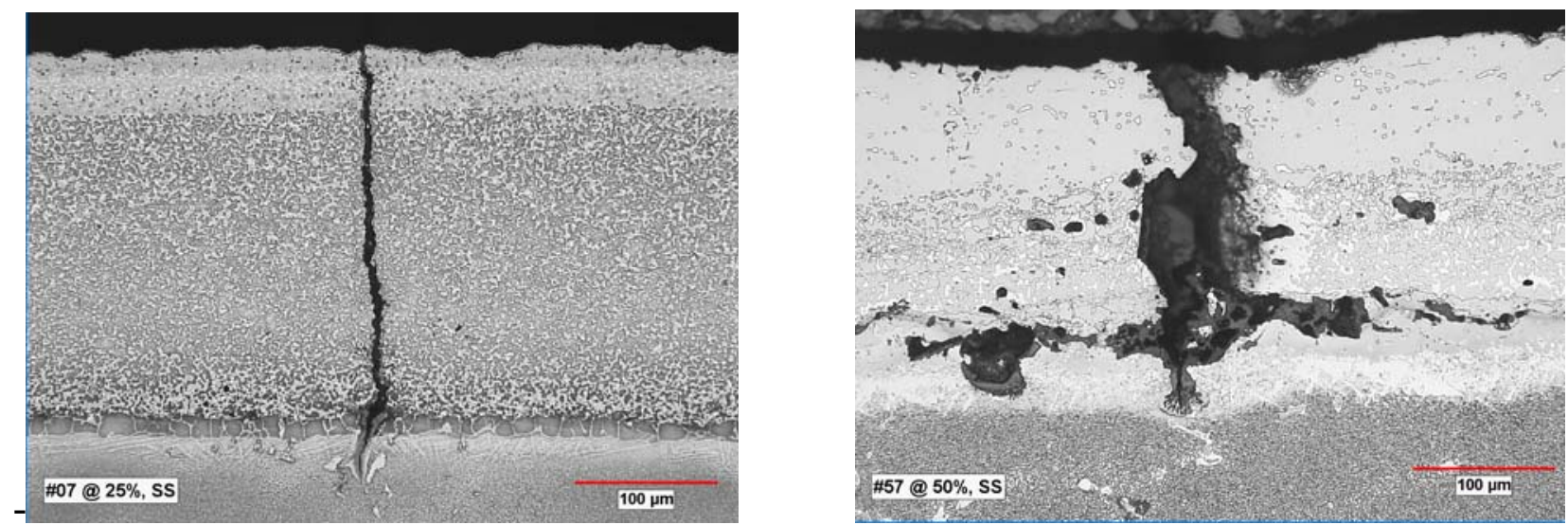

Figure 7-3 Optical Microgrphs of sections of Blades 7 and 57 Showing TMF Cracks 
The quality of the coating on Blade 57 was poor. The thickness of MCrAlY and aluminide coatings on this blade was not uniform. In addition, several grit particles were observed at the MCrAlY/substrate interface. Blade 7 exhibited an uniform top aluminde $(0.002$ inch thick) layer both on the convex and concave sides of the airfoil. Variation of the quality of the coating on the two blades is compared in Figure 7-4.

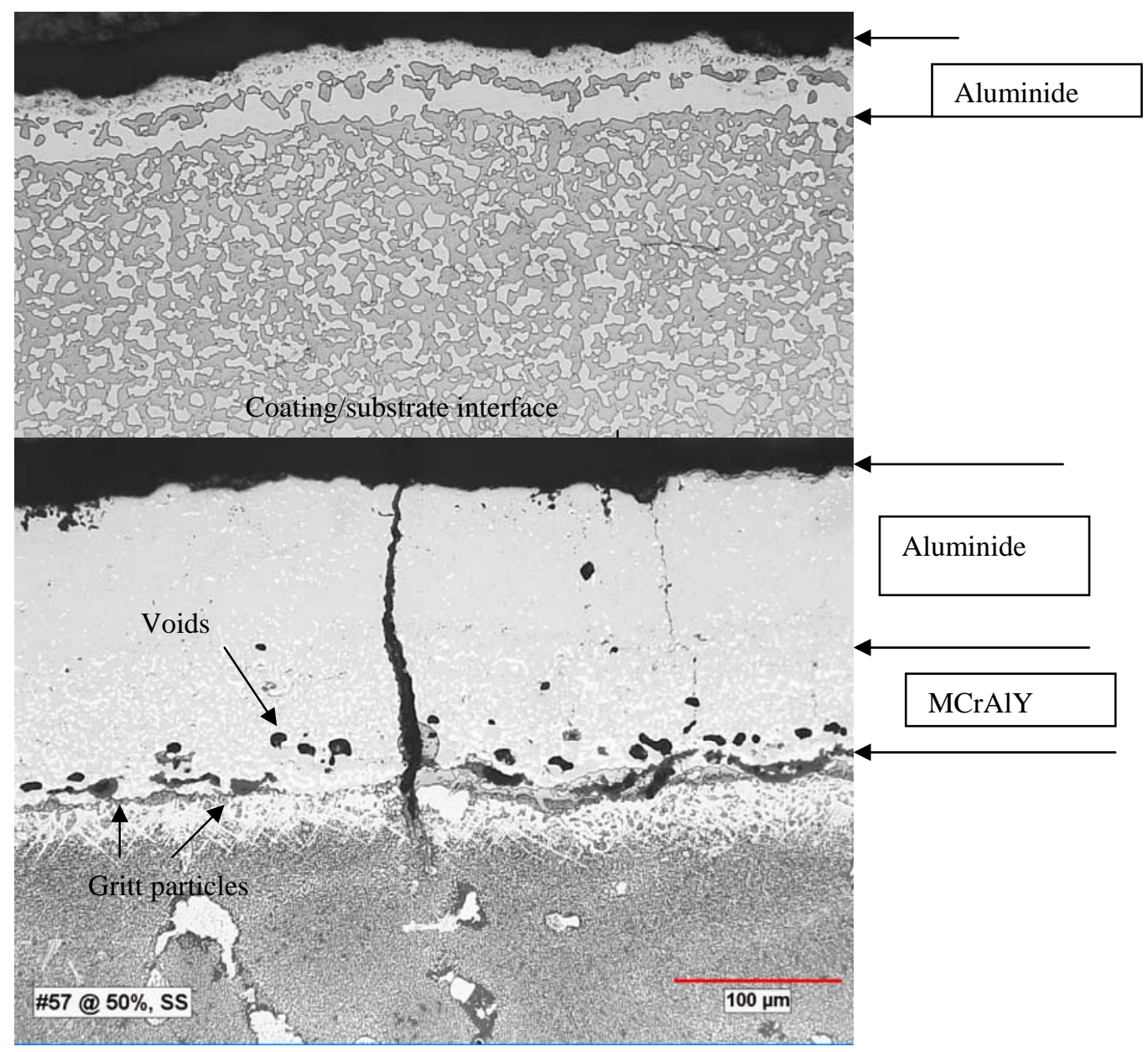

Figure 7-4. Optical micrographs of coating on Blade 57 and 7 showing variation of aluminde/MCrAlY thickness and grit particle contamination at the coating/substrate interface.

Energy dipersive spectroscopy (EDS) analysis was performed at several locations on the mounts to determine the chemical composition of the coatings. Typical results are presented in Table 7-1. The results showed that the aluminum content in the MCrAlY coating on Blade 57 was significantly higher than that of coating on Blade 7 . The higher aluminum content in the coating may have contributed for extensive TMF cracking of Blade 57. 
Table 7-1: Semi-quantitative chemical composition of coatings, wt\%.

\begin{tabular}{|l|l|l|l|l|l|l|l|}
\hline Blade & Coating & $\mathrm{Al}$ & $\mathrm{Ti}$ & $\mathrm{Cr}$ & $\mathrm{Co}$ & $\mathrm{Y}$ & $\mathrm{Ni}$ \\
\hline \# 7, CX @ 25\% & Aluminide & 18.5 & - & 15.5 & 24.6 & - & Balance \\
\hline & MCrAIY & 10.9 & 0.4 & 19.7 & 33.2 & 0.4 & Balance \\
\hline \# 57, CX @ 25\% & Aluminide & 21.5 & - & 9.9 & 31.3 & - & Balance \\
\hline & MCrAIY & 13.5 & 0.5 & 23.2 & 28.8 & 0.4 & Balance \\
\hline
\end{tabular}

